\title{
Estimativa da evolução do uso final de energia elétrica no setor residencial do Brasil por região geográfica
}

\author{
Estimation of development of electricity end-use by the \\ residential sector in Brazil by geographic region
}

\section{Karla Cristina de Freitas Jorge Abrahão Roberta Gonçalves Vieira de Souza}

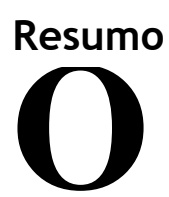

presente trabalho estimou a estrutura de consumo de energia elétrica no setor residencial por uso final, dos anos 2005 e 2019, desagregado por região geográfica brasileira. A metodologia utilizou os dados da pesquisa Posse e Hábitos de Uso de

Equipamentos Elétricos na Classe Residencial dos anos 2004-2006 e 20182019 e a aplicação de técnicas estatísticas. Os resultados identificaram que a evolução da estrutura de consumo possui singularidades regionais. As principais evoluções na estrutura estimada entre 2005 e 2019 foram a ampliação do consumo por uso final dos equipamentos da categoria conforto ambiental e a permanência de uma elevada participação no consumo dos equipamentos da categoria conservação de alimentos. Houve redução da participação da categoria aquecimento de água em todas as regiões, exceto na região Sul. Houve predomínio do consumo por uso final de equipamentos das categorias conforto ambiental, aquecimento de água e conservação de alimentos variando entre $82 \%$ e $91 \%$ em função da região geográfica. As conclusões indicam elevado potencial para implementação de medidas de eficiência energética, no entanto se ressalta que o padrão de consumo regional deve ser considerado para que os resultados sejam efetivos.

Palavras-chave: Energia elétrica. Uso final de energia elétrica. Setor residencial. Região geográfica. Consumo de energia elétrica.

\begin{abstract}
The study estimates the structure of end-use electricity consumption by residential sector in the years 2005 and 2019, segregated by each Brazilian geographic region. The method used data from the survey of Household Appliances and Consumption Habits from the years 2004-2006 and 2018-2019 and applied statistical techniques. The results showed regional singularities in the development of the consumption structure. The main developments in the estimated structure between the years 2005 and 2019 were an increase in the end-use consumption in the Environmental Comfort Appliances category, and the continued high participation of the consumption of the Food Conservation category. There was a decrease in the share of Water Heating category enduse consumption in all regions, except in the South. The study also showed a predominance of end-use consumption of appliances in the Environmental Comfort, Heating Water and Food Conservation categories, ranging from $82 \%$ to $91 \%$ according to the different regions. The findings indicate high potential for implementing energy efficiency measures, however, it must be stressed that regional consumption patterns must be considered in order to achieve effective results.
\end{abstract}

Keywords: Electricity. Electricity end-use. Residential sector. Geographic region. Electricity consumption. 


\section{Introdução}

A energia elétrica é a segunda maior fonte energética consumida no Brasil, atrás apenas do petróleo e derivados (EMPRESA..., 2019). O crescimento do consumo de energia elétrica é um movimento global associado ao desenvolvimento das sociedades e à qualidade de vida e saúde (SOUZA et al., 2013; FERREIRA NETO; CORRÊA; PEROBELLI, 2019). Apesar dos avanços em eficiência energética, no período entre 2000 e 2019 esse consumo cresceu a uma taxa média geométrica anual de 2,8\% no Brasil (EMPRESA..., 2019). A preocupação do crescimento contínuo do consumo está relacionada à segurança energética e à necessidade de ampliação da capacidade instalada (OLIVEIRA; REBELATTO, 2015; FERREIRA NETO; CORRÊA; PEROBELLI, 2019). Em 2018, a oferta interna de energia elétrica foi de $636,4 \mathrm{TWh}$, da qual uma parcela de 35,0 TWh foi importada. Esse total equivale a 2,3\% da geração mundial (EMPRESA..., 2019).

O setor residencial vem sendo pesquisado globalmente devido à relevante participação e ao crescimento do consumo de energia elétrica. De forma geral, as pesquisas envolvem diferentes abordagens e metodologias (GUO et al., 2018; IQBAL; KUTT; ROSIN, 2018). Focadas inicialmente em indicadores econômicos e aspectos físicos e técnicos dos edifícios, as análises ampliaram-se para as interações entre variáveis demográficas, domiciliares, econômicas e ambientais (LIDDLE, 2011, 2014; FERREIRA NETO; CORRÊA; PEROBELLI, 2019; ALBRECHT et al., 2020; ESTIRI; ZAGHENI, 2019). Como ponto comum, diversas pesquisas destacam a importância de desagregar as análises regionalmente, dessa forma incorporando as dimensões históricas, culturais e comportamentais (LIDDLE, 2014; TSO; GUAN, 2014; JONES; FUERTES; LOMAS, 2015).

Este trabalho tem, portanto, como objetivo estimar e apresentar o consumo de energia elétrica do setor residencial por uso final em nível nacional e desagregado por região geográfica para os anos 2005 e 2019 . A relevância deste estudo refere-se ao preenchimento da lacuna da determinação de cenários de uso final para esses anos. A metodologia para o desenvolvimento dos cenários de uso final utilizou como base os dados da pesquisa Posse e Hábitos de Uso de Equipamentos Elétricos na Classe Residencial (PPH) dos anos 20042006 e 2018-2019 (ELETROBRAS, 2007, 2019). Espera-se que os resultados deste trabalho contribuam para futuras pesquisas voltadas ao setor residencial, além de servir para a construção de programas e para o detalhamento regional da política energética brasileira.

\section{Referencial teórico}

\section{Cenário do consumo de energia elétrica no setor residencial}

No Brasil, o consumo de energia elétrica pelo setor residencial em 2019 foi de 141.929 GWh, equivalente a 29,4\% do consumo total, um incremento de 69,7\% em relação ao ano 2000 (EMPRESA..., 2019). Como pode ser visto no Quadro 1, no período 2000-2020, em cenário de pós-crise de abastecimento elétrico, houve a incorporação de diversos marcos institucionais, como a reestruturação do setor elétrico brasileiro e a implementação da Lei de Eficiência Energética (BRASIL, 2001). Alguns desses programas e políticas, com demandas diferenciadas regionalmente, colaboraram com o incremento do consumo, tais como Luz no Campo (BRASIL, 1999) e Luz para Todos (BRASIL, 2002), com o objetivo de ampliação da taxa de acessibilidade à rede de energia elétrica; Bolsa Família (BRASIL, 2004), programa de distribuição de renda; e Minha Casa, Minha Vida (BRASIL, 2009), programa de redução do déficit habitacional. O programa Minha Casa, Minha Vida (MCMV) entregou 4,1 milhões de domicílios no período 2009-2018, inseridos no setor elétrico brasileiro como novos consumidores. Desse montante, 54\% das novas unidades habitacionais localizam-se nas regiões Sudeste e Sul, e 28\% na região Nordeste. Já os resultados do Bolsa Família indicam que $47 \%$ das famílias beneficiadas moram na região Nordeste (BRASIL, 2009; DATASEBRAE, 2016; MOREIRA; SILVEIRA; EUCLYDES, 2017). Os programas de distribuição de renda, associados ao cenário de baixa taxa de juros, ampliaram a capacidade das famílias de aumentar a posse de eletrodomésticos, principalmente para aquelas que saíram da faixa de pobreza (ACHÃO; SCHAEFFER, 2009). Como ponto favorável ao incremento do consumo, tem-se a política Tarifa Social (BRASIL, 2010), que beneficia, mediante descontos, as classes de menor consumo e, dessa forma, alivia o peso da conta de energia na despesa domiciliar. No sentido contrário, favorecendo a redução do consumo e implementados para desacelerar a curva da demanda de consumo de energia elétrica pelo setor residencial, no médio e longo prazo, há os programas de eficiência energética, como o Programa Brasileiro de Etiquetagem (PBE), voltado para a implementação da etiquetagem do nível de eficiência energética de equipamentos eletrônicos e de edifícios (MORISHITA; GHISI, 2010). Em 2020, o PBE contemplava 33 programas voltados a 
eletrodomésticos. Com relação as edificações residenciais, considera-se pequena a participação da etiquetagem, ainda voluntária; 91\% das etiquetas emitidas concentram-se na região Sudeste (INSTITUTO NACIONAL..., 2019).

\section{Variáveis que influenciam o consumo de energia elétrica no setor residencial}

O Brasil possui uma vasta literatura científica voltada para o setor residencial no intuito de avançar a compreensão das variáveis que influenciam o consumo de energia elétrica, da qual se destacam os resultados apresentados a seguir.

O setor apresenta alta dependência da rede de fornecimento, uma vez que 99,5\% dos domicílios utilizam a energia elétrica proveniente das concessionárias, sendo apenas $0,12 \%$ do consumo gerado no próprio domicílio (SIQUEIRA; CORDEIRO JUNIOR; CASTELAR, 2006; ELETROBRAS, 2019). Diante dessa dependência, análises de sensibilidade do consumo por sazonalidade, tarifa e renda familiar são frequentes na literatura. A sensibilidade do consumo do setor à sazonalidade e as variações climáticas foi observada por alguns estudos, sendo verificada a ampliação do uso do ar-condicionado e do ventilador principalmente nas regiões de clima quente e no verão, e do uso de aquecedores ambientais e de aquecimento de água no inverno e em regiões de clima frio (OLIVEIRA; SILVEIRA; BRAGA, 2000; ALMEIDA; SCHAEFFER; LA ROVERE, 2001; GHISI; GOSCH; LAMBERTS, 2007; ELETROBRAS, 2019).

Quadro 1 - Programas e políticas nacionais com impacto sobre o consumo de energia elétrica do setor residencial brasileiro e resultados efetivos de sua implementação no período de 2000 a 2020

\begin{tabular}{|c|c|c|}
\hline Período & Programa/Política & Resultados \\
\hline $2000-2020$ & $\begin{array}{l}\text { Luz no Campo } \\
\text { (BRASIL, 1999) }\end{array}$ & $\begin{array}{l}\text { Ampliação dos níveis de eletrificação das áreas rurais de } \\
19 \% \text { no ano de } 2003 \text { para } 68 \% \text { em } 2014^{\text {a }}\end{array}$ \\
\hline 2001-atual & $\begin{array}{l}\text { Programa Brasileiro de } \\
\text { Etiquetagem - } \\
\text { Equipamentos e sistemas } \\
\text { eletrodomésticos } \\
\text { (BRASIL, 2001) }\end{array}$ & $\begin{array}{l}\text { Implementação de } 33 \text { programas de etiquetagem de } \\
\text { eficiência energética de eletrodomésticos e sistemas } \\
\text { elétricos voltados ao setor residencial }{ }^{\mathrm{b}}\end{array}$ \\
\hline $2003-2020$ & $\begin{array}{l}\text { Luz para Todos } \\
\text { (BRASIL, 2002) }\end{array}$ & $\begin{array}{l}\text { Ampliação dos níveis de eletrificação das áreas urbanas de } \\
97,0 \% \text { para 99,8\%; exceto na região Norte }\end{array}$ \\
\hline 2003-atual & $\begin{array}{l}\text { Bolsa Família (BRASIL, } \\
\text { 2004) }\end{array}$ & $\begin{array}{l}\text { Benefício concedido a } 14,39 \text { milhões de famílias com } \\
\text { domicílios nas seguintes regiões: } 47 \% \text { Nordeste; } 25 \% \\
\text { Sudeste; } 18 \% \text { Norte; } 5 \% \text { Sul; e } 5 \% \text { Centro-Oeste }\end{array}$ \\
\hline 2005-atual & Redução de juros & $\begin{array}{l}\text { Redução de juros de } 1,38 \% \text { em janeiro de } 2000 \text { para } 0,63 \% \\
\text { em setembro de } 2019^{e^{*}}\end{array}$ \\
\hline 2009-atual & $\begin{array}{l}\text { Minha Casa Minha Vida } \\
\text { (BRASIL, 2009) }\end{array}$ & $\begin{array}{l}\text { Entrega de } 4,1 \text { milhões de unidades habitacionais no } \\
\text { período } 2009-2018 \text { e previsão de entrega adicional de } 1,5 \\
\text { milhão de habitações em obra }\end{array}$ \\
\hline 2010-atual & $\begin{array}{l}\text { Tarifa Social de Energia } \\
\text { Elétrica (BRASIL, 2010) }\end{array}$ & $\begin{array}{l}\text { Benefício de desconto progressivo variável de } 0 \% \text { a } 65 \% \\
\text { para unidades consumidoras enquadradas na Subclasse } \\
\text { Residencial Baixa Renda com o consumo elétrico mensal } \\
\text { até } 220 \mathrm{KWh}^{\mathrm{g}}\end{array}$ \\
\hline 2011-atual & $\begin{array}{l}\text { Programa Brasileiro de } \\
\text { Etiquetagem - Edifícios } \\
\text { Residenciais }\end{array}$ & $\begin{array}{l}\text { Etiquetagem de } 323 \text { edifícios multifamiliares (615 etiquetas } \\
\text { emitidas, sendo } 318 \text { etiquetas de projeto e } 297 \text { etiquetas } \\
\text { inspeção), e de } 4.055 \text { unidades habitacionais autônomas } \\
\text { (5.460 etiquetas emitidas, sendo } 2.844 \text { etiquetas de projeto } \\
\text { e } 2.616 \text { etiquetas de inspeção) }\end{array}$ \\
\hline
\end{tabular}

Fonte: elaboração a partir de (a) IBGE (INSTITUTO BRASILEIRO..., 2019); (b) Inmetro (INSTITUTO NACIONAL..., 2020); (c) IBGE (INSTITUTO BRASILEIRO..., 2004, 2019); (d) DATASEBRAE (2016); (e) Banco Central do Brasil (2019); (f) Brasil (2019); e (g) ANEEL (AGÊNCIA..., 2019).

Nota: *no período 2000-2019 houve variação das taxas de juros, com taxa máxima mensal dos juros de 2,21 (junho/2003), taxa mínima mensal de 0,28 (março/2000) e taxa mediana de 1,34 (setembro e outubro/2010) (BANCO..., 2019). 
O consumo de energia elétrica no domicílio apresenta sensibilidade negativa ao preço da tarifa elétrica e positiva à renda familiar (MODIANO, 1984; ANDRADE; LOBÃO, 1997; SCHMIDT; LIMA, 2004; MATTOS; LIMA, 2005; SIQUEIRA; CORDEIRO JUNIOR; CASTELAR, 2006; IRFFI et al., 2009). Silva et al. (2014) identificaram alta correlação do consumo residencial com a renda familiar e com o número de pessoas por domicílio. O aumento da renda familiar tem o efeito de acelerar o consumo residencial em curto prazo devido ao crescimento da posse de equipamentos eletrodomésticos (ACHÃO; SCHAEFFER, 2009; WOLFRAM; SHELEF; GERTLER, 2012; BANCO..., 2014; FERREIRA NETO; CORREAA; PEROBELLI, 2019). Ainda, o aumento no custo dos eletrodomésticos mostrou ter efeito maior sobre o consumo de energia elétrica do que o aumento no preço tarifário (SCHMIDT; LIMA, 2004; SIQUEIRA; CORDEIRO JUNIOR; CASTELAR, 2006).

Ferreira Neto, Corrêa e Perobelli (2019) apontaram causalidade do consumo residencial de energia elétrica sobre o crescimento econômico, indicando um impacto negativo sobre a economia quando da restrição do consumo. Nesse sentido, observa-se que as crises econômicas ocorridas nos períodos 2008-2009 e 20142015 foram coincidentes com os curtos períodos de redução do consumo de energia elétrica, observando-se ainda uma rápida recuperação do consumo após o cenário de crise (INSTITUTO BRASILEIRO..., 2018; EMPRESA..., 2019).

Os processos sociais e culturais ocorridos no Brasil nas últimas décadas, como o aumento da taxa de escolaridade, o aumento da participação feminina no mercado de trabalho, as alterações nos cargos de chefia domiciliar, o envelhecimento populacional e a mudança dos arranjos familiares, alteraram a dinâmica da vida doméstica e tiveram impacto no consumo de energia elétrica. A introdução de certos eletrodomésticos no domicílio, como lava-roupas, secadoras, lava-louças, panela elétrica, forno de micro-ondas, forno elétrico e aspirador de pó, contribuiu para facilitar e reduzir a jornada de trabalho doméstico, inclusive influenciando o aumento da taxa ativa de mulheres no mercado de trabalho (BARBOSA, 2014).

Os domicílios unipessoais apresentaram crescimento de 35\% no período 2004-2013, passando de $10 \%$ em 2004 para 13,5\% em 2013, com maiores proporções desse tipo de arranjo localizadas nas regiões Sul $(14,9 \%)$ e Sudeste $(14,5 \%)$ (INSTITUTO BRASILEIRO..., 2019). Por sua vez, o aumento dos domicílios unipessoais, conformados por diferentes idades da população, principalmente pela faixa etária de idosos (BARBOSA, 2014; INSTITUTO BRASILEIRO..., 2014a), impactou o consumo do setor, uma vez que os eletrodomésticos passaram a ser compartilhados por um menor número de pessoas.

A tendência de urbanização, os menores índices de ocupação e as dificuldades de mobilidade, de forma geral, contribuem para que os idosos passem mais horas do dia no domicílio, assistindo a televisão, usando dispositivos eletrônicos e interativos e outros eletrodomésticos (INSTITUTO BRASILEIRO..., 2014a). Em estudos que consideraram aspectos demográficos relacionados ao consumo de energia elétrica, Liddle (2011) e Estiri e Zagheni (2019) identificaram a influência positiva da população idosa no consumo residencial de energia elétrica.

\section{Edificações e o consumo de energia elétrica no setor residencial}

No contexto das edificações, as principais medidas de eficiência energética estão associadas a sua etiquetagem, ainda com modesta disseminação em relação ao parque construído, e ao controle restritivo dos níveis de consumo de aparelhos eletrônicos e eletrodomésticos.

Com efeito, a política de regulação dos índices de eficiência energética dos eletrodomésticos ainda apresenta elevado potencial para reduzir a necessidade de expansão da matriz elétrica e a demanda de pico horária e sazonal, principalmente no atual cenário da manutenção de programas de inserção social (MORISHITA; GHISI, 2010; OLIVEIRA; REBELATTO, 2015; COSTA et al., 2019; PROJETO KIGALI, 2019).

No que tange ao uso dos aparelhos de ar condicionado, a introdução da tecnologia inverter, que regula o fluxo de energia do sistema alterando a velocidade do compressor e reduzindo o consumo de energia, foi identificada como uma oportunidade para o mercado de eficiência energética. A partir desse aspecto foi indicada a revisão do Programa Brasileiro de Etiquetagem para prever a adoção de método de ensaio sazonal para os aparelhos de ar condicionado, de forma a avaliar mais adequadamente o desempenho desses aparelhos com tecnologia inverter (COSTA et al., 2019; PROJETO KIGALI, 2019).

Em relação às edificações, estima-se que os critérios incorporados no projeto das edificações para o conforto humano e bem-estar ainda são restritos por questões econômicas (ALBRECHT et al., 2020). Além disso, os projetos de habitações de interesse social são tecnicamente pouco viáveis e flexíveis para permitir adaptações futuras relacionadas principalmente ao conforto térmico (BORTOLI; VILLA, 2020).

386 Abrahão, K. C. de F. J.; Souza, R. G. V. de 


\section{Regiões geográficas e o consumo de energia elétrica no setor residencial}

Através da análise de dados de consumo residencial e de suas interações com as dimensões da população e do número de domicílios, observa-se uma dinâmica diversificada entre as regiões devido às diferenças geográficas, sociais, culturais, econômicas, ambientais e políticas, entre outras (Figura 1).

Exemplificando, a região Nordeste, comparada à região Sul, tem quase o dobro do contingente populacional, um número de domicílios $23 \%$ maior, e seu consumo anual per capita é aproximadamente 1,5 vez menor. De outro lado, as regiões Centro-Oeste, Sudeste e Sul, com maiores índices do PIB per capita, apresentam os maiores índices de consumo residencial per capita em diferentes cenários de área territorial, contingente populacional e número de domicílios. Essas análises preliminares reforçam a necessidade de se compreender o padrão particular regional na forma do uso da energia elétrica, uma vez que seus resultados podem fornecer dados mais detalhados para alimentar os delineamentos das políticas públicas e energéticas por região do país.

\section{Estimativa de energia elétrica por uso final}

Os modelos de análise energética, de forma geral, podem ser classificados em dois tipos de abordagem: topdown e bottom-up. Tal como sugerem os nomes, a abordagem top-down analisa as relações energéticas a partir da perspectiva de um nível mais amplo para os níveis inferiores, enquanto a abordagem bottom-up foca na descrição de sistemas de energia menos amplos ou individuais. Devido a sua própria perspectiva de análise, a abordagem bottom-up pode fornecer informações mais detalhadas, como efeitos e comportamentos de um setor específico (KEMFERT, 2005).

A estimativa do consumo de energia elétrica por uso final no setor residencial, em geral, possui a abordagem do tipo bottom-up, sendo uma metodologia utilizada por agências internacionais, como a United States Energy Administration Information e a European Environment Agency, para estimar o percentual médio de consumo anual de cada equipamento. As análises da estrutura de consumo por uso final auxiliam o planejamento de políticas e programas de eficiência energética voltados ao setor residencial, pois permitem quantificar o grau de relevância do consumo de cada equipamento ou de grupos de equipamentos. $\mathrm{O}$ consumo por uso final está associado aos índices de posse, à potência, ao tempo e ao hábito de uso de cada equipamento. O levantamento de dados para a aplicação da metodologia de uso final para o setor residencial é uma tarefa complexa, podendo ser feita, no mínimo, de duas formas:

(a) através de medição histórica de consumo em uma amostragem de domicílios, como realizado por Silva et al. (2014), o que requer a instalação e o monitoramento de medidores por uso final, além da coleta de dados dos equipamentos e do domicílio; e

(b) através de aplicação de questionários e entrevistas a uma amostragem de domicílios, como as pesquisas Posse de Eletrodomésticos e Hábitos de Uso (PPH) realizadas pela Eletrobras (1988, 1998, 2007, 2019) em âmbito nacional.

Figura 1 - Área territorial (\%); projeção da população (\%); domicílios com acesso à energia elétrica (\%); consumo residencial de energia elétrica (\%); consumo residencial de energia elétrica per capita (KWh/capita): regiões geográficas, ano 2018; produto interno bruto (PIB) regional per capita, ano 2017 (R\$ 105\%capita)

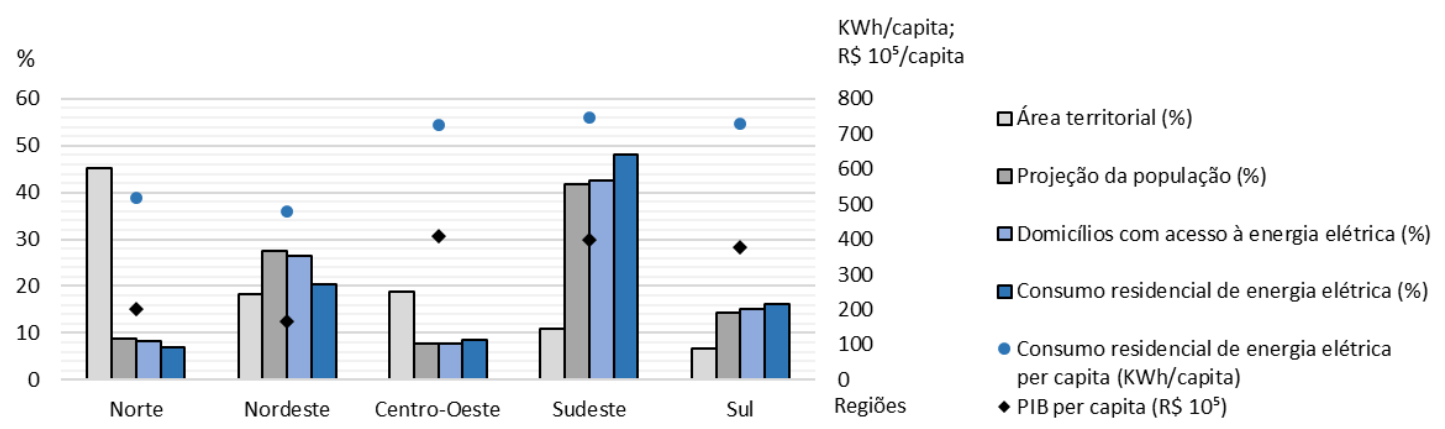

Fonte: elaboração a partir de IBGE (INSTITUTO BRASILEIRO..., 2018, 2019) e EPE (EMPRESA..., 2019). 
Uma vez coletados e organizados os dados, as análises de uso final podem ser feitas por meio da aplicação de técnicas estatísticas (JANUZZI; SCHIPPER, 1991; ALMEIDA; SCHAEFFER; LA ROVERE, 2001; GHISI; GOSCH; LAMBERTS, 2007; SWAN; UGURSAL, 2009; SILVA et al., 2014).

As pesquisas PPH reúnem dados dos domicílios brasileiros e servem de fonte para estudos com abordagem na construção de cenários de uso final de energia elétrica por equipamentos. Atualmente em sua quarta edição, as pesquisas PPH anteriores a 2019 foram realizadas nos anos 1987, 1997-1998 e 2004-2006. As PPH de 1987 e de 1997-1998 tiveram a amostragem de 10.818 e 15.870 domicílios respectivamente (ELETROBRAS, 1988, 1998). As características da amostragem das PPH de 2004-2006 e de 2018-2019 são comparadas na seção de metodologia.

A Tabela 1 reúne resultados de estudos que estimaram o consumo residencial de energia elétrica por uso final no Brasil, entre 1987 e 2012. Observa-se que a geladeira apresentou uma participação relativa variável entre $29,9 \%$ e $41 \%$ do consumo de energia elétrica. Maior participação do uso final da lava-roupas e do freezer entre 1987 e 1997-1999 pôde ser interpretada como parte do processo social e mudança cultural, quando a inserção de eletrodomésticos colabora para a redução do tempo dedicado ao trabalho doméstico. No estudo de Almeida, Schaeffer e La Rovere (2001) avançou-se a percepção de uma dinâmica diferenciada entre as regiões, principalmente no que diz respeito ao uso final do chuveiro elétrico e do ar-condicionado na região Norte. Os resultados do estudo de Silva et al. (2014), com recorte amostral limitado aos domicílios de baixa renda e a sua localização específica, apresentam a cultura do uso do chuveiro intensificada em região de clima frio e um relevante espaço para implementação de política de eficiência energética para esse equipamento (JANUZZI; SCHIPPER, 1991; ALMEIDA; SCHAEFFER; LA ROVERE, 2001; GHISI; GOSCH; LAMBERTS, 2007; SILVA et al., 2014).

Tabela 1 - Uso final de energia elétrica do setor residencial no Brasil e regiões, anos 1987, 1997, 19971999 e 2012 (\%)

\begin{tabular}{|c|c|c|c|c|c|c|c|c|c|}
\hline \multirow{3}{*}{$\begin{array}{c}\text { Ano da análise } \\
\text { de uso final }\end{array}$} & \multirow{3}{*}{$\begin{array}{c}\begin{array}{c}\text { Januzzi e } \\
\text { Schipper } \\
\text { (1991) }\end{array} \\
1987 \\
\text { Brasil } \\
\end{array}$} & \multicolumn{6}{|c|}{$\begin{array}{c}\text { Almeida, Schaeffer e La Rovere } \\
\text { (2001) }\end{array}$} & \multirow{3}{*}{$\begin{array}{c}\begin{array}{c}\text { Ghisi, } \\
\text { Gosch e } \\
\text { Lamberts } \\
(2007)\end{array} \\
1997-1999 \\
\text { Brasil } \\
\end{array}$} & \multirow{3}{*}{$\begin{array}{c}\begin{array}{c}\text { Silva } \text { et } \\
\text { al. } \\
(2014)\end{array} \\
2012 \\
(*)\end{array}$} \\
\hline & & \multicolumn{6}{|c|}{1997} & & \\
\hline & & Brasil & $\mathbf{N}$ & NE & $\mathrm{CO}$ & SE & $\mathbf{S}$ & & \\
\hline Ar-condicionado & 7,0 & 3,0 & 9,4 & 3,1 & 2,3 & 3,3 & 1,5 & 10,0 & 0,0 \\
\hline Chuveiro elétrico & 23,0 & 20,7 & 4,5 & 7,2 & 23,2 & 23,4 & 22,4 & 20,0 & 36,8 \\
\hline $\begin{array}{l}\text { Aquecedor } \\
\text { elétrico }\end{array}$ & 1,0 & - & - & - & - & - & - & - & - \\
\hline Freezer & 4,0 & - & - & - & - & - & - & 9,0 & - \\
\hline Geladeira & 33,0 & 34,1 & 35,4 & 41,0 & 33,6 & 33,1 & 32,6 & 33,0 & 29,9 \\
\hline $\begin{array}{l}\text { Forno de micro- } \\
\text { ondas }\end{array}$ & - & - & - & - & - & - & - & 1,0 & 0,6 \\
\hline Iluminação & 12,0 & 12,3 & 19,6 & 18,2 & 12,1 & 11,2 & 10,9 & 11,0 & 5,2 \\
\hline Ferro elétrico & 2,0 & - & - & - & - & - & - & 3,0 & - \\
\hline Lava-roupas & 1,0 & - & - & - & - & - & - & 2,0 & 0,9 \\
\hline $\begin{array}{l}\text { Secadora de } \\
\text { roupas }\end{array}$ & 0,0 & - & - & - & - & - & - & - & - \\
\hline Televisão & 6,0 & - & - & - & - & - & - & 5,0 & 10,2 \\
\hline Aparelho de som & - & - & - & - & - & - & - & 5,0 & - \\
\hline Outros & 11,0 & 29,9 & 31,1 & 30,5 & 28,9 & 29,0 & 32,7 & - & 10,5 \\
\hline
\end{tabular}

Fonte: elaboração a partir de Januzzi e Schipper (1991), Almeida, Schaeffer e La Rovere (2001), Ghisi, Gosch e Lamberts (2007) e Silva et al. (2014).

Nota: (*) a amostragem do estudo limitou-se a 60 domicílios da região metropolitana de Florianópolis, classificados como de baixa renda familiar pelo Plano Municipal de Habitação de Interesse Social, e os resultados acima apresentados referem-se ao uso final médio de energia elétrica. 
Como apresentado, o setor residencial é dinâmico, e o consumo de energia elétrica apresenta sensibilidade a diferentes aspectos. O uso final de energia elétrica se modifica ao longo do tempo por mudança da renda familiar, por inserção de novos modelos e tecnologias de equipamentos, por mudanças na cultura de uso, pela modificação dos níveis de consumo dos equipamentos, entre outros.

No final de 2019 ocorreu a mais recente publicação da pesquisa PPH, realizada nos anos 2018 e 2019. A interrupção dessa pesquisa nos últimos 12 anos deixou uma lacuna na compreensão da relação entre o consumo de energia elétrica e os demais processos sociais, culturais, econômicos e políticos vivenciados nesse período, o que inclui as estimativas potenciais de redução da participação do consumo relativo pelas ações da política de eficiência energética. Para compreender essa lacuna, Abrahão (2015) estimou os cenários regionais de consumo por uso final para os anos 2015 e 2020 a partir de índices da evolução nacional da produção e venda de equipamentos eletrodomésticos voltados ao setor residencial. Esses índices, estimados pelos dados disponibilizados pelo IBGE (INSTITUTO BRASILEIRO..., 2014b), mostraram que os equipamentos de ar condicionado, máquinas de lavar e de secar roupas, micro-ondas, aquecedores de água e microcomputadores portáteis tiveram as maiores taxas de crescimento médio geométrico anual para o período 2005-2012, tanto para produção quanto para venda, equivalendo a respectivamente $16 \%, 11 \%, 17 \%$, $42 \%$ e $72 \%$. De acordo com essa pesquisa, para o mesmo período, as lâmpadas incandescentes apresentaram decrescimento médio geométrico de $22 \%$, enquanto os aparelhos de DVD (digital versatile disc) e videocassete, rádios e combinados mostraram crescimento médio geométrico positivo na produção e negativo nas vendas. As variações positivas de crescimento da produção e da venda de equipamentos foram interpretadas como níveis de transferências desses equipamentos do mercado para os domicílios, enquanto as taxas de crescimento de vendas inferiores aos níveis de produção foram interpretadas como estoque de equipamentos retidos no mercado, seja por tecnologia ultrapassada, seja por modificação na cultura de uso (ABRAHÃO, 2015). Exemplos de modificação na cultura de uso identificados à época foram a redução do uso e da posse da enceradeira e da máquina de costura doméstica, e a ampliação da venda de máquinas de lavar roupas e de lavar louças. Como exemplo de tecnologia ultrapassada teve-se a redução da posse de lâmpadas incandescentes, rádio-relógio, aparelhos de fax e videocassetes, cada vez com menor presença nos domicílios, substituídos por tecnologias mais eficientes, como as lâmpadas LED (lighting emitting diode) e os dispositivos eletrônicos pessoais. Como introdução de tecnologia houve os dispositivos de segurança como as câmeras, os bebedouros e purificadores de água, as máquinas de lavar louças e secadoras, o telefone celular, o notebook e outros dispositivos de uso pessoal. Ademais, foi identificada nessa pesquisa a tendência de universalização da posse de aparelhos com conectividade, como conversores digitais, receptores de canais de televisão por assinatura, modems de internet e roteadores sem fio (INSTITUTO BRASILEIRO..., 2014b; ABRAHÃO, 2015; ELETROBRAS, 2019).

\section{Metodologia}

Com o objetivo de estimar o uso final de energia elétrica para os anos 2005 e 2019 foram desenvolvidas as seguintes etapas neste trabalho:

(a) levantamento, tratamento e organização dos dados;

(b) determinação do coeficiente de ajuste do tempo médio de uso de equipamentos;

(c) técnica analítica para estimativa da estrutura de consumo por uso final; e

(d) determinação do erro global do estudo.

\section{Levantamento, tratamento e organização dos dados}

O estudo partiu do levantamento de uma estrutura de dados dos anos 2005 e 2019 organizados por regiões geográficas. As cinco regiões geográficas brasileiras, neste trabalho, foram denotadas como " $j$ " e identificadas como N, NE, CO, SE e S.

As pesquisas PPH dos anos 2004-2006 (ELETROBRAS, 2007) e 2018-2019 (ELETROBRAS, 2019) foram a base para o desenvolvimento deste estudo, seguindo a metodologia de Abrahão (2015). Das pesquisas PPH foram levantados os dados regionais do número de domicílios, número de pessoas por domicílio e posse e hábito de uso de eletrodomésticos. Os dados de consumo anual residencial regional de energia elétrica dos anos 2005 e 2019 foram levantados de EPE (EMPRESA..., 2019). Os equipamentos eletrodomésticos foram denotados como " $i$ ", e para uma melhor compreensão dos resultados foram organizados em seis categorias de uso, conforme Achão (2003) e Schaeffer et al. (2003): conforto ambiental, aquecimento de água, conservação de alimentos, iluminação, serviços gerais e lazer. 


\section{Características da amostragem das pesquisas PPH}

As pesquisas PPH dos anos 2004-2006 (ELETROBRAS, 2007) e 2018-2019 (ELETROBRAS, 2019) tiveram a amostragem de 9.847 e 18.775 domicílios respectivamente, localizados em todas as regiões geográficas. A PPH 2004-2006 utilizou um plano amostral com a seleção dos domicílios entrevistados distribuídos em seis faixas de consumo, com resultados apresentados agregados em três faixas de consumo de energia elétrica, e localizados em 16 estados e no Distrito Federal. Já a PPH 2018-2019 utilizou um plano amostral selecionando os domicílios por classes econômicas, com distribuição proporcional por região geográfica. As entrevistas da PPH 2018-2019 foram limitadas às áreas urbanas, de capitais e de cidades com número de domicílios igual ou superior a 100.000 unidades, formalmente ligados à rede de distribuição de energia elétrica. Em média, $98,5 \%$ dos domicílios entrevistados eram utilizados para atividades exclusivamente residenciais.

\section{Dados regionais: consumo de energia elétrica, número de domicílios e número de pessoas por domicílio}

Os dados utilizados neste trabalho foram levantados de fontes oficiais e apresentam-se resumidos no Quadro 2.

\section{Número de equipamentos por domicílio (nEDji)}

Os dados de índice da posse média de equipamentos, denotados por $\mathrm{nED}$, e referentes ao número de equipamentos por domicílio, foram levantados nas pesquisas PPH dos anos 2004-2006 (ELETROBRAS, 2007) e 2018-2019 (ELETROBRAS, 2019). Os valores adotados para nEDji ${ }_{2005}$ enEDji 2019 apresentam-se na Tabela 2.

Considerando-se relevante incorporar a posse dos aparelhos celulares, adotou-se o índice de posse do ano 2005 da Pesquisa Nacional por Amostras de Domicílio (PNAD) (INSTITUTO BRASILEIRO..., 2006).

\section{Potência média e tempo médio de uso dos equipamentos}

A potência média dos eletrodomésticos, denotada por " $p_{i}(\mathrm{~W})$ ", e o tempo médio mensal de uso dos equipamentos, denotado por " $t_{m}(\mathrm{~h})$ ", foram levantados de diversas fontes, tendo sido observadas divergências de medidas em alguns casos (ELETROBRAS, 2007, 2019; COMPANHIA DE ELETRICIDADE..., 2012; COMPANHIA PAULISTA..., 2012; COMPANHIA..., 2014; INSTITUTO NACIONAL..., 2020). Logo, este estudo realizou um procedimento de ajuste desses dados, determinando-se medidas para os dados de potência $\left(p_{i}, \mathrm{~W}\right)$ e de tempo médio mensal de uso de equipamentos $\left(t_{m} ; \mathrm{h} / \mathrm{mês}\right)$, conforme apresenta a Tabela 3 e de acordo com a metodologia de Abrahão (2015).

Foi ainda necessário determinar uma equivalência entre o tempo médio mensal de uso de equipamentos $\left(t_{m}\right.$; $\mathrm{h} /$ mês) e os quatro níveis de tempo médio de hábito de uso $\left(T_{m} H_{u}\right)$ qualitativos, constantes nas pesquisas PPH. Na PPH 2004-2006 o hábito de uso foi tratado como "grau de utilização", enquanto na PPH 2018-2019 utilizou-se o termo "frequência de uso", sendo correspondentes a uso intenso e grande $\left(T_{m} H_{u}\right.$-gr $)$; uso médio $\left(T_{m} H_{u}-m d\right)$; uso regular $\left(T_{m} H_{u}-r g\right)$; uso mínimo e pequeno $\left(T_{m} H_{u}-p q\right)$. Não foi considerado o grau de uso eventual de equipamentos, qualitativo ou horário, apresentados nas pesquisas PPH, exceto para as lâmpadas.

Quadro 2 - Notação e dados levantados dos anos de 2005 e 2019 por regiões geográficas: consumo (C; $\mathrm{MWh}$ ); número de domicílios ( $\mathrm{nD})$; e número de pessoas por domicílio (nPD)

\begin{tabular}{|c|c|c|c|c|c|c|}
\hline Notação & N & NE & CO & SE & S & Fonte \\
\hline $\mathrm{C}_{2005}$ & 4292906 & 13392580 & 6289008 & 44991169 & 13678593 & EPE (EMPRESA..., 2020) \\
$\mathrm{C}_{2019}$ & 9467062 & 28973658 & 12642126 & 68169921 & 22676861 & EPE (EMPRESA..., 2020) \\
$\mathrm{nD}_{2005}$ & 2491066 & 11794802 & 3463732 & 23748325 & 7122993 & Eletrobras (2007) \\
$\mathrm{nD}_{2019}$ & 5786327 & 19364187 & 5737824 & 29201674 & 10937507 & Eletrobras (2019) \\
$\mathrm{nPD}_{2005}$ & 3,78 & 3,54 & 2,94 & 3,39 & 2,97 & Eletrobras (2007) \\
$\mathrm{nPD}_{2019}$ & 3,81 & 3,47 & 3,49 & 3,11 & 3,18 & Eletrobras (2019) \\
\hline
\end{tabular}

Fonte: elaboração a partir de Eletrobras (2007, 2019) e EPE (EMPRESA..., 2020).

Nota: 1) $C_{y}$ corresponde ao consumo anual residencial de energia elétrica medido na rede para o ano y $(M W h) ; \mathrm{nD}_{\mathrm{y}}$ corresponde ao número de domicílios do ano y; e nPDy corresponde ao número de pessoas por domicílios do ano y. 2) 0 número de pessoas por domicílio considerado neste estudo foi caracterizado na PPH como moradores habituais. 
Tabela 2 - Número médio de equipamentos “i” por domicílio, por categoria de uso e por região “ $j$ ”, anos 2005 e 2019 (Continua...)

\begin{tabular}{|c|c|c|c|c|c|c|c|c|c|c|c|}
\hline \multirow{2}{*}{ Categorias } & \multirow{2}{*}{ Equipamentos (i) $^{1}$} & \multicolumn{5}{|c|}{ nED 2005 - Regiões } & \multicolumn{5}{|c|}{ nED 2019 - Regiões } \\
\hline & & $\mathbf{N}$ & NE & $\mathrm{CO}$ & SE & $\mathbf{S}$ & $\mathbf{N}$ & NE & $\mathrm{CO}$ & SE & $\mathbf{S}$ \\
\hline \multirow{4}{*}{$\begin{array}{l}\text { Conforto } \\
\text { ambiental }\end{array}$} & Ar-condicionado & 0,27 & 0,20 & 0,15 & 0,09 & 0,25 & 0,40 & 0,06 & 0,20 & 0,22 & 0,32 \\
\hline & Ventilador de teto & 0,43 & 0,43 & 0,42 & 0,44 & 0,79 & 0,04 & 0,02 & 0,08 & 0,35 & 0,14 \\
\hline & Ventilador portátil & 1,45 & 0,96 & 0,89 & 0,53 & 1,10 & 1,53 & 1,41 & 1,33 & 0,90 & 0,91 \\
\hline & Aquecedor de ambiente & 0,00 & 0,01 & 0,01 & 0,01 & 0,08 & 0,00 & 0,00 & 0,00 & 0,01 & 0,03 \\
\hline \multirow{2}{*}{$\begin{array}{l}\text { Aquecimento } \\
\text { de água }\end{array}$} & Chuveiro - chave verão & 0,05 & 0,40 & 1,08 & 1,10 & 1,17 & 0,04 & 0,10 & 0,93 & 0,92 & 1,12 \\
\hline & Chuveiro - chave inverno & 0,05 & 0,40 & 1,08 & 1,10 & 1,17 & 0,04 & 0,10 & 0,93 & 0,92 & 1,12 \\
\hline \multirow{2}{*}{$\begin{array}{l}\text { Conservação } \\
\text { de alimentos }\end{array}$} & Freezer & 0,17 & 0,18 & 0,16 & 0,22 & 0,46 & 0,13 & 0,09 & 0,19 & 0,32 & 0,18 \\
\hline & Geladeira & 0,95 & 0,95 & 1,02 & 1,02 & 1,01 & 1,02 & 1,00 & 1,00 & 1,04 & 1,05 \\
\hline \multirow{8}{*}{ Iluminação } & Incandescente $(\mathrm{t} 1)^{2}$ & 0,69 & 0,68 & 1,24 & 2,25 & 1,50 & 0,41 & 0,21 & 0,39 & 0,99 & 1,06 \\
\hline & Incandescente $(\mathrm{t} 2)^{2}$ & 1,22 & 2,40 & 3,06 & 3,11 & 1,28 & 0,01 & 0,01 & 0,01 & 0,05 & 0,04 \\
\hline & Fluorescente $(\mathrm{t} 1)^{2}$ & 1,66 & 1,53 & 1,30 & 1,77 & 2,55 & 3,80 & 3,85 & 4,09 & 3,25 & 2,50 \\
\hline & Fluorescente $(\mathrm{t} 2)^{2}$ & 3,32 & 3,02 & 2,79 & 1,59 & 2,76 & 0,08 & 0,12 & 0,14 & 0,17 & 0,11 \\
\hline & Dicroica e outras $(\mathrm{t} 1)^{2}$ & 0,03 & 0,02 & 0,05 & 0,04 & 0,05 & 0,02 & 0,03 & 0,01 & 0,19 & 0,11 \\
\hline & Dicroica e outras $(\mathrm{t} 2)^{2}$ & 0,04 & 0,06 & 0,11 & 0,06 & 0,04 & 0,00 & 0,00 & 0,00 & 0,01 & 0,00 \\
\hline & $\operatorname{LED}(\mathrm{t} 1)^{2,3}$ & - & - & - & - & - & 1,57 & 1,77 & 2,48 & 2,40 & 2,87 \\
\hline & $\operatorname{LED}(\mathrm{t} 2)^{2,3}$ & - & - & - & - & - & 0,03 & 0,05 & 0,09 & 0,13 & 0,12 \\
\hline \multirow{36}{*}{ Serviços gerais } & Aspirador de pó & 0,02 & 0,03 & 0,04 & 0,12 & 0,22 & 0,02 & 0,02 & 0,05 & 0,15 & 0,33 \\
\hline & Batedeira & 0,24 & 0,37 & 0,43 & 0,49 & 0,66 & 0,13 & 0,22 & 0,33 & 0,28 & 0,37 \\
\hline & Bebedouro/purificador ${ }^{3}$ & - & - & - & - & - & 0,09 & 0,08 & 0,08 & 0,10 & 0,03 \\
\hline & Bomba d'água & 0,12 & 0,09 & 0,03 & 0,04 & 0,02 & 0,12 & 0,04 & 0,02 & 0,04 & 0,01 \\
\hline & Cafeteira & 0,04 & 0,11 & 0,03 & 0,17 & 0,46 & 0,05 & 0,05 & 0,09 & 0,20 & 0,35 \\
\hline & Chapinha ${ }^{3}$ & - & - & - & - & - & 0,18 & 0,26 & 0,30 & 0,24 & 0,24 \\
\hline & Ebulidor $^{3}$ & - & - & - & - & - & 0,00 & 0,00 & 0,01 & 0,01 & 0,02 \\
\hline & Enceradeira & 0,01 & 0,01 & 0,01 & 0,08 & 0,15 & 0,00 & 0,00 & 0,00 & 0,02 & 0,01 \\
\hline & Espremedor de frutas ${ }^{3}$ & - & - & - & - & - & 0,04 & 0,10 & 0,14 & 0,20 & 0,09 \\
\hline & Exaustor $^{3}$ & 0,00 & 0,06 & 0,02 & 0,07 & 0,32 & - & - & - & - & - \\
\hline & Faca elétrica ${ }^{3}$ & - & - & - & - & - & 0,00 & 0,00 & 0,00 & 0,01 & 0,01 \\
\hline & Ferro elétrico & 0,77 & 0,91 & 0,92 & 0,94 & 0,96 & 0,36 & 0,61 & 0,54 & 0,35 & 0,15 \\
\hline & Ferro elétrico a vapor ${ }^{3}$ & - & - & - & - & - & 0,06 & 0,06 & 0,20 & 0,34 & 0,29 \\
\hline & Filtro de piscina ${ }^{3}$ & - & - & - & - & - & 0,00 & 0,00 & 0,00 & 0,01 & 0,02 \\
\hline & Fogão elétrico ${ }^{3}$ & - & - & - & - & - & 0,03 & 0,01 & 0,02 & 0,06 & 0,14 \\
\hline & Forno elétrico & 0,01 & 0,02 & 0,07 & 0,09 & 0,10 & 0,03 & 0,01 & 0,20 & 0,09 & 0,39 \\
\hline & Forno de micro-ondas & 0,08 & 0,15 & 0,24 & 0,37 & 0,40 & 0,26 & 0,36 & 0,58 & 0,65 & 0,81 \\
\hline & Fritadeira elétrica $^{3}$ & - & - & - & - & - & 0,03 & 0,02 & 0,09 & 0,10 & 0,08 \\
\hline & Furadeira ${ }^{3}$ & - & - & - & - & - & 0,03 & 0,03 & 0,04 & 0,09 & 0,15 \\
\hline & Lava-louças & 0,01 & 0,01 & 0,03 & 0,04 & 0,13 & 0,00 & 0,00 & 0,01 & 0,03 & 0,04 \\
\hline & Lava-jato & 0,00 & 0,00 & 0,00 & 0,00 & 0,00 & 0,01 & 0,01 & 0,03 & 0,02 & 0,09 \\
\hline & Lava-roupas & 0,55 & 0,35 & 0,73 & 0,74 & 0,77 & 0,64 & 0,44 & 0,87 & 0,82 & 0,92 \\
\hline & Liquidificador & 0,70 & 0,83 & 0,78 & 0,82 & 0,88 & 0,75 & 0,93 & 0,90 & 0,83 & 0,81 \\
\hline & Máquina de costura & 0,05 & 0,07 & 0,03 & 0,06 & 0,03 & 0,04 & 0,05 & 0,05 & 0,07 & 0,08 \\
\hline & Máquina de solda ${ }^{3}$ & - & - & - & - & - & 0,01 & 0,00 & 0,00 & 0,01 & 0,02 \\
\hline & Multiprocessador ${ }^{3}$ & - & - & - & - & - & 0,01 & 0,02 & 0,02 & 0,09 & 0,06 \\
\hline & Panela elétrica & 0,00 & 0,00 & 0,00 & 0,00 & 0,02 & 0,03 & 0,01 & 0,13 & 0,10 & 0,08 \\
\hline & Panificadora ${ }^{3}$ & - & - & - & - & - & 0,00 & 0,00 & 0,00 & 0,01 & 0,03 \\
\hline & Portão eletrônico ${ }^{3}$ & - & - & - & - & - & 0,04 & 0,01 & 0,10 & 0,05 & 0,15 \\
\hline & Sanduicheira ${ }^{3}$ & - & - & - & - & - & 0,25 & 0,34 & 0,36 & 0,31 & 0,38 \\
\hline & Secador de cabelo ${ }^{3}$ & - & - & - & - & - & 0,14 & 0,15 & 0,24 & 0,30 & 0,46 \\
\hline & Secadora de roupas & 0,00 & 0,04 & 0,01 & 0,04 & 0,39 & 0,00 & 0,00 & 0,00 & 0,01 & 0,04 \\
\hline & Secadora de roupas centrífuga ${ }^{3}$ & - & - & - & - & - & 0,09 & 0,03 & 0,10 & 0,02 & 0,05 \\
\hline & Serra elétrica ${ }^{3}$ & - & - & - & - & - & 0,01 & 0,00 & 0,01 & 0,01 & 0,02 \\
\hline & Torneira elétrica & 0,00 & 0,00 & 0,00 & 0,02 & 0,01 & - & - & - & - & - \\
\hline & Triturador de lixo ${ }^{3}$ & - & - & - & - & - & 0,00 & 0,00 & 0,00 & 0,01 & 0,01 \\
\hline
\end{tabular}

Fonte: elaboração a partir de Eletrobras (2007, 2019) e IBGE (INSTITUTO BRASILEIRO..., 2014b).

Nota: (1) Devido ao baixo índice de posse média nas regiões, este trabalho desconsiderou os seguintes equipamentos: fax, hidromassagem, projetores (iluminação de jardim) e adega. (2) Nos dados de posse de lâmpadas, a indicação "t1" refere-se à posse média de uso habitual, e "t2", posse média de uso eventual. Utilizou-se o fator de uso, habitual e eventual, das lâmpadas incandescentes, por região, para as lâmpadas dicroicas, uma vez que o fator de uso destas lâmpadas não constou nas duas pesquisas PPH. Na pesquisa PPH 2018-2019 não houve a especificação de posse média por uso por tipo de lâmpada. Dessa forma, utilizou-se o fator de uso, habitual e eventual, de forma homogênea para todos os tipos de lâmpadas. As lâmpadas LED agruparam as tipologias tuboLED, LED compacta, dicroica LED e minidicroica LED da pesquisa PPH 2018-2019. (3) Os equipamentos com dados de posse não apresentados na Tabela 2 não foram contemplados nas pesquisas de posse $\mathrm{PPH}$. 
Tabela 2 - Número médio de equipamentos “ $i$ ” por domicílio, por categoria de uso e por região “ $j$ ”, anos 2005 e 2019 (continuação)

\begin{tabular}{|c|c|c|c|c|c|c|c|c|c|c|c|}
\hline \multirow{2}{*}{ Categorias } & \multirow{2}{*}{ Equipamentos (i) $^{1}$} & \multicolumn{5}{|c|}{ nED 2005 - Regiões } & \multicolumn{5}{|c|}{ nED 2019 - Regiões } \\
\hline & & $\mathbf{N}$ & $\mathbf{N E}$ & $\mathrm{CO}$ & SE & $\mathbf{S}$ & $\mathbf{N}$ & NE & $\mathrm{CO}$ & SE & $\mathbf{S}$ \\
\hline \multirow{18}{*}{ Lazer } & Celular & 0,27 & 0,24 & 0,33 & 0,19 & 0,30 & 2,28 & 2,24 & 2,55 & 2,08 & 2,20 \\
\hline & Conversor digital TV aberta ${ }^{3}$ & - & - & - & - & - & 0,16 & 0,19 & 0,12 & 0,11 & 0,18 \\
\hline & DVD $^{4}$ & 0,25 & 0,22 & 0,31 & 0,20 & 0,42 & 0,24 & 0,45 & 0,37 & 0,42 & 0,29 \\
\hline & Impressora & 0,10 & 0,14 & 0,15 & 0,14 & 0,15 & 0,04 & 0,04 & 0,05 & 0,09 & 0,06 \\
\hline & Microcomputador & 0,13 & 0,18 & 0,26 & 0,24 & 0,27 & 0,11 & 0,11 & 0,20 & 0,28 & 0,32 \\
\hline & Modem de internet ${ }^{3}$ & - & - & - & - & - & 0,24 & 0,38 & 0,57 & 0,32 & 0,45 \\
\hline & Nobreak $^{3}$ & - & - & - & - & - & 0,01 & 0,01 & 0,01 & 0,04 & 0,02 \\
\hline & Notebook $^{3}$ & - & - & - & - & - & 0,24 & 0,19 & 0,33 & 0,41 & 0,41 \\
\hline & Rádio elétrico & 0,28 & 0,17 & 0,33 & 0,49 & 0,20 & - & - & - & - & - \\
\hline & Receptor digital externo ${ }^{3}$ & - & - & - & - & - & 0,06 & 0,07 & 0,07 & 0,05 & 0,06 \\
\hline & Receptor digital TV por assinatura & 0,04 & 0,12 & 0,05 & 0,11 & 0,54 & 0,10 & 0,09 & 0,16 & 0,23 & 0,38 \\
\hline & Roteador sem fio ${ }^{3}$ & - & - & - & - & - & 0,06 & 0,08 & 0,03 & 0,15 & 0,16 \\
\hline & Som ${ }^{5}$ & 0,47 & 0,75 & 0,60 & 0,73 & 0,90 & 0,12 & 0,29 & 0,18 & 0,22 & 0,25 \\
\hline & Tablet $^{3}$ & - & - & - & - & - & 0,04 & 0,05 & 0,05 & 0,15 & 0,08 \\
\hline & Telefone sem fio ${ }^{3}$ & - & - & - & - & - & 0,03 & 0,01 & 0,03 & 0,10 & 0,12 \\
\hline & Televisão & 1,16 & 1,30 & 1,24 & 1,46 & 1,63 & 1,18 & 1,26 & 1,19 & 1,47 & 1,42 \\
\hline & Videocasse & 0,16 & 0,22 & 0,17 & 0,41 & 0,33 & - & - & - & - & - \\
\hline & Videogame & 0,03 & 0,07 & 0,05 & 0,10 & 0,09 & 0,03 & 0,03 & 0,06 & 0,07 & 0,08 \\
\hline
\end{tabular}

Fonte: elaboração a partir de Eletrobras $(2007,2019)$ e IBGE (INSTITUTO BRASILEIRO..., 2014b).

Nota: (3) Os equipamentos com dados de posse não apresentados na Tabela 2 não foram contemplados nas pesquisas de posse PPH. (4) A posse do DVD na pesquisa PPH 2018-2019 agrupou a posse dos equipamentos DVD, videocassete e bluray. (5) A posse do som na pesquisa PPH 2018-2019 agrupou a posse de equipamentos de som e rádio. (6) Foi desconsiderada a posse média de fritadeira sem óleo, visto que sua posse foi inferior à posse da fritadeira elétrica com óleo.

Este trabalho considerou, assim como Abrahão (2015), que o tempo médio mensal de uso de equipamentos corresponde ao hábito de uso médio da pesquisa $\mathrm{PPH}$, ou seja, $t_{m}=T_{m} H_{u-m d}$. A partir dessa equivalência, foram atribuídos pesos relativos para cada nível qualitativo de hábito de uso da pesquisa PPH, a fim de converter esses níveis qualitativos em níveis quantitativos, referentes a uma medida de tempo de hora por mês. Determinou-se que $100 \%$ do tempo médio mensal de uso de um equipamento refere-se ao peso do nível de hábito de uso médio da PPH. Em seguida, determinaram-se os pesos de $150 \%$ para o hábito de uso intenso e grande, $25 \%$ para o hábito de uso regular, e $12,5 \%$ para o hábito mínimo e pequeno. Dessa forma, determinaram-se quatro níveis de tempo de uso de equipamentos, apresentados na Tabela 3, de acordo com a metodologia de Abrahão (2015).

\section{Determinação do coeficiente de ajuste do tempo médio de uso de equipamentos $(k t)$}

Após a conversão dos níveis de hábito de uso $(H u)$ por medida de tempo (h/mês), este trabalho estimou um coeficiente de ajuste de tempo, expresso por $k t$, para ajustar o tempo médio mensal de uso $\left(t_{m}\right)$ de cada equipamento "i" através da Equação 1, segundo a metodologia de Abrahão (2015) para cada região geográfica. Esse coeficiente foi determinado considerando-se o tempo médio mensal de uso $\left(T_{m} H_{u}\right)$ e a parcela de uso dos equipamentos $(\mathrm{Pu})$, levantada nas pesquisas $\mathrm{PPH}$, podendo ser interpretado como a intensidade de uso do equipamento.

$$
\mathrm{kt}_{i j}=\frac{\sum_{i ; j}^{n}(\mathrm{TmHu} \mathrm{Pu})}{\sum_{i ; j}^{n} \mathrm{TmHu}}
$$

Onde:

$k t$ expressa o coeficiente de ajuste do tempo médio de uso de cada equipamento;

$i$ expressa o equipamento eletrodoméstico;

$j$ expressa a região geográfica;

$T_{m} H_{u}$ (h/mês) expressa o tempo médio mensal de uso do equipamento de acordo com o nível do hábito de uso, dado pela pesquisa $\mathrm{PPH}$; e

$P u(\%)$ expressa a parcela de uso do equipamento, dado pela pesquisa $\mathrm{PPH}$. 
Tabela 3 - Categorias, equipamentos, medidas adotadas de potência $\left(p_{i}, W\right)$; tempo médio de uso $\left(t_{m}\right.$, h); tempo médio mensal por hábito de uso $\left(T_{m} H_{u}\right)$ por aparelho " $i$ "; e atribuição de pesos (Continua...)

\begin{tabular}{|c|c|c|c|c|c|c|c|}
\hline \multirow{4}{*}{ Categorias } & \multirow{4}{*}{ Equipamentos (i) } & \multirow{3}{*}{ Potência } & \multirow{3}{*}{$\begin{array}{l}\text { Tempo } \\
\text { médio } \\
\text { de uso }\end{array}$} & \multicolumn{4}{|c|}{ Tempo médio mensal por hábito de uso } \\
\hline & & & & \multirow{2}{*}{$\begin{array}{c}\begin{array}{c}\text { Intenso e } \\
\text { grande }\end{array} \\
\text { Peso: } \\
150 \%\end{array}$} & \multirow{2}{*}{$\begin{array}{c}\text { Médio } \\
\text { Peso: } \\
100 \%\end{array}$} & \multirow{2}{*}{$\begin{array}{c}\text { Regular } \\
\text { Peso: } 25 \%\end{array}$} & $\begin{array}{c}\text { Mínimo e } \\
\text { pequeno }\end{array}$ \\
\hline & & & & & & & $\begin{array}{l}\text { Peso: } \\
12,5 \%\end{array}$ \\
\hline & & $p(\mathbf{W})$ & $\begin{array}{c}\text { tm } \\
\text { (h/mês) }\end{array}$ & $\begin{array}{c}\text { TmHu-gr } \\
\text { (h/mês) }\end{array}$ & $\begin{array}{c}\text { TmHu-md } \\
\text { (h/mês) }\end{array}$ & $\begin{array}{c}\text { TmHu-rg } \\
\text { (h/mês) }\end{array}$ & $\begin{array}{c}\text { TmHu-pq } \\
\text { (h/mês) }\end{array}$ \\
\hline \multirow{4}{*}{$\begin{array}{l}\text { Conforto } \\
\text { ambiental }\end{array}$} & Ar-condicionado & 1000 & 64,00 & 96,00 & 64,00 & 16,00 & 8,00 \\
\hline & Ventilador de teto & 120 & 240,00 & 360,00 & 240,00 & 60,00 & 30,00 \\
\hline & Ventilador portátil & 120 & 240,00 & 360,00 & 240,00 & 60,00 & 30,00 \\
\hline & Aquecedor de ambiente & 1500 & 10,00 & 15,00 & 10,00 & 2,50 & 1,25 \\
\hline \multirow{2}{*}{$\begin{array}{l}\text { Aquecimento } \\
\text { de água }\end{array}$} & Chuveiro - chave verão & 2700 & 5,00 & 7,50 & 5,00 & 1,25 & 0,63 \\
\hline & Chuveiro - chave inverno & 5400 & 5,00 & 7,50 & 5,00 & 1,25 & 0,63 \\
\hline \multirow{2}{*}{$\begin{array}{l}\text { Conservação de } \\
\text { alimentos }\end{array}$} & Freezer & 200 & 360,00 & 540,00 & 360,00 & 90,00 & 45,00 \\
\hline & Geladeira & 250 & 360,00 & 540,00 & 360,00 & 90,00 & 45,00 \\
\hline \multirow{8}{*}{ Iluminação } & Incandescente (t1) & $60 / 50^{1}$ & 90,00 & 135,00 & 90,00 & 22,50 & 11,25 \\
\hline & Incandescente (t2) & $60 / 50^{1}$ & 5,00 & 7,50 & 5,00 & 1,25 & 0,63 \\
\hline & Fluorescente (t1) & $22 / 13^{1}$ & 90,00 & 135,00 & 90,00 & 22,50 & 11,25 \\
\hline & Fluorescente (t2) & $22 / 13^{1}$ & 5,00 & 7,50 & 5,00 & 1,25 & 0,63 \\
\hline & Dicroica e outras (t1) & $43 / 26^{1}$ & 90,00 & 135,00 & 90,00 & 22,50 & 11,25 \\
\hline & Dicroica e outras (t2) & $43 / 26^{1}$ & 5,00 & 7,50 & 5,00 & 1,25 & 0,63 \\
\hline & $\operatorname{LED}(\mathrm{t} 1)$ & $17^{1}$ & 90,00 & 135,00 & 90,00 & 22,50 & 11,25 \\
\hline & $\operatorname{LED}(\mathrm{t} 2)$ & $17^{1}$ & 5,00 & 7,50 & 5,00 & 1,25 & 0,63 \\
\hline \multirow{36}{*}{ Serviços gerais } & Aspirador de pó & 1000 & 3,80 & 5,70 & 3,80 & 0,95 & 0,48 \\
\hline & Batedeira & 200 & 3,00 & 4,50 & 3,00 & 0,75 & 0,38 \\
\hline & Bebedouro purificador & 100 & 360,00 & 540,00 & 360,00 & 90,00 & 45,00 \\
\hline & Bomba d'água & 1500 & 9,00 & 13,50 & 9,00 & 2,25 & 1,13 \\
\hline & Cafeteira & 600 & 8,00 & 12,00 & 8,00 & 2,00 & 1,00 \\
\hline & Chapinha & 60 & 3,00 & 4,50 & 3,00 & 0,75 & 0,38 \\
\hline & Ebulidor & 1000 & 3,00 & 4,50 & 3,00 & 0,75 & 0,38 \\
\hline & Enceradeira & 300 & 15,00 & 22,50 & 15,00 & 3,75 & 1,88 \\
\hline & Espremedor de frutas & 50 & 3,00 & 4,50 & 3,00 & 0,75 & 0,38 \\
\hline & Exaustor & 300 & 15,00 & 22,50 & 15,00 & 3,75 & 1,88 \\
\hline & Faca elétrica & 100 & 2,00 & 3,00 & 2,00 & 0,50 & 0,25 \\
\hline & Ferro elétrico & 1000 & 8,00 & 12,00 & 8,00 & 2,00 & 1,00 \\
\hline & Ferro elétrico a vapor & 1000 & 8,00 & 1200 & 8,00 & 2,00 & 1,00 \\
\hline & Filtro de piscina & 1100 & 4,00 & 6,00 & 4,00 & 1,00 & 0,50 \\
\hline & Fogão elétrico & 90 & 4,00 & 6,00 & 4,00 & 1,00 & 0,50 \\
\hline & Forno elétrico & 1500 & 15,00 & 22,50 & 15,00 & 3,75 & 1,88 \\
\hline & Forno de micro-ondas & 1300 & 10,00 & 15,00 & 10,00 & 2,50 & 1,25 \\
\hline & Fritadeira elétrica & 1200 & 4,00 & 6,00 & 4,00 & 1,00 & 0,50 \\
\hline & Furadeira & 700 & 3,00 & 4,50 & 3,00 & 0,75 & 0,38 \\
\hline & Lava-louças & 1500 & 10,00 & 15,00 & 10,00 & 2,50 & 1,25 \\
\hline & Lava-jato & 1500 & 4,00 & 6,00 & 4,00 & 1,00 & 0,50 \\
\hline & Lava-roupas & 1000 & 12,00 & 18,00 & 12,00 & 3,00 & 1,50 \\
\hline & Liquidificador & 300 & 4,00 & 6,00 & 4,00 & 1,00 & 0,50 \\
\hline & Máquina de costura & 100 & 3,00 & 4,50 & 3,00 & 0,75 & 0,38 \\
\hline & Máquina de solda & 2200 & 16,00 & 24,00 & 16,00 & 4,00 & 2,00 \\
\hline & Multiprocessador & 250 & 4,00 & 6,00 & 4,00 & 1,00 & 0,50 \\
\hline & Panela elétrica & 1000 & 4,00 & 6,00 & 4,00 & 1,00 & 0,50 \\
\hline & Panificadora & 600 & 16,00 & 24,00 & 16,00 & 4,00 & 2,00 \\
\hline & Portão eletrônico & 180 & 4,00 & 6,00 & 4,00 & 1,00 & 0,50 \\
\hline & Sanduicheira & 640 & 3,00 & 4,50 & 3,00 & 0,75 & 0,38 \\
\hline & Secador de cabelo & 1250 & 3,00 & 4,50 & 3,00 & 0,75 & 0,38 \\
\hline & Secadora de roupas & 3000 & 12,00 & 18,00 & 12,00 & 3,00 & 1,50 \\
\hline & Secadora de roupas centrífuga & 2000 & 12,00 & 18,00 & 12,00 & 3,00 & 1,50 \\
\hline & Serra elétrica & 1500 & 1,00 & 1,50 & 1,00 & 0,25 & 0,13 \\
\hline & Torneira elétrica & 5500 & 4,00 & 6,00 & 4,00 & 1,00 & 0,50 \\
\hline & Triturador de lixo & 600 & 4,00 & 6,00 & 4,00 & 1,00 & 0,50 \\
\hline
\end{tabular}

Fonte: elaboração a partir de Eletrobras (2007), Coelba (COMPANHIA DE ELETRICIDADE..., 2012), CPFL (COMPANHIA PAULISTA..., 2012), Cemig (COMPANHIA..., 2014), Inmetro (INSTITUTO NACIONAL..., 2020) e Abrahão (2015).

Nota: (1) Para as lâmpadas incandescentes, fluorescentes e dicroicas, foram apresentadas duas medidas de potência, referindo-se as medidas utilizadas na estrutura de uso final do ano 2005 e do ano 2019 respectivamente. Essas medidas, incluindo a potência das lâmpadas LED, foram estimadas a partir da média ponderada de dados de posse e de potência das pesquisas PPH, considerando as diversas variedades de modelos de lâmpadas para cada um de seus tipos (incandescentes, fluorescentes, dicroicas e outros, e LED). 
Tabela 3 - Categorias de equipamentos, equipamentos, valores adotados de potência $\left(p_{i}, W\right)$; tempo médio de uso $\left(t_{m}, h\right)$; tempo médio mensal por hábito de uso $\left(T_{m} H_{u}\right)$ por aparelho " $i$ ”; e atribuição de pesos (continuação)

\begin{tabular}{|c|c|c|c|c|c|c|c|}
\hline \multirow{4}{*}{ Categorias } & \multirow{4}{*}{ Equipamentos (i) } & \multirow{3}{*}{ Potência } & \multirow{3}{*}{$\begin{array}{l}\text { Tempo } \\
\text { médio } \\
\text { de uso }\end{array}$} & \multicolumn{4}{|c|}{ Tempo médio mensal por hábito de uso } \\
\hline & & & & $\begin{array}{c}\text { Intenso e } \\
\text { grande }\end{array}$ & Médio & Regular & $\begin{array}{l}\text { Mínimo e } \\
\text { pequeno }\end{array}$ \\
\hline & & & & Peso: $150 \%$ & Peso: $100 \%$ & Peso: $25 \%$ & Peso: $12,5 \%$ \\
\hline & & $p(\mathbf{W})$ & $\begin{array}{c}t m \\
\text { (h/mês) }\end{array}$ & $\begin{array}{c}\text { TmHu-gr } \\
\text { (h/mês) }\end{array}$ & $\begin{array}{c}\text { TmHu-md } \\
\text { (h/mês) }\end{array}$ & $\begin{array}{c}\text { TmHu-rg } \\
\text { (h/mês) }\end{array}$ & $\begin{array}{c}\text { TmHu-pq } \\
\text { (h/mês) }\end{array}$ \\
\hline \multirow{18}{*}{ Lazer } & Celular & 5 & 30,00 & 45,00 & 30,00 & 7,50 & 3,75 \\
\hline & Conversor digital TV aberta & 10 & 360,00 & 540,00 & 360,00 & 90,00 & 45,00 \\
\hline & DVD & 50 & 16,00 & 24,00 & 16,00 & 4,00 & 2,00 \\
\hline & Impressora & 400 & 10,00 & 15,00 & 10,00 & 2,50 & 1,25 \\
\hline & Microcomputador & 150 & 90,00 & 135,00 & 90,00 & 22,50 & 11,25 \\
\hline & Modem de internet & 10 & 360,00 & 540,00 & 360,00 & 90,00 & 45,00 \\
\hline & Nobreak & 80 & 28,00 & 42,00 & 28,00 & 7,00 & 3,50 \\
\hline & Notebook & 65 & 28,00 & 42,00 & 28,00 & 7,00 & 3,50 \\
\hline & Rádio elétrico & 50 & 60,00 & 90,00 & 60,00 & 15,00 & 7,50 \\
\hline & Receptor digital externo & 10 & 360,00 & 540,00 & 360,00 & 90,00 & 45,00 \\
\hline & Receptor digital TV assinatura & 10 & 360,00 & 540,00 & 360,00 & 90,00 & 45,00 \\
\hline & Roteador sem fio & 10 & 360,00 & 540,00 & 360,00 & 90,00 & 45,00 \\
\hline & Som & 150 & 15,00 & 22,50 & 15,00 & 3,75 & 1,88 \\
\hline & Tablet & 10 & 16,00 & 24,00 & 16,00 & 4,00 & 2,00 \\
\hline & Telefone sem fio & 4 & 240,00 & 360,00 & 240,00 & 60,00 & 30,00 \\
\hline & Televisão & 100 & 15,00 & 22,50 & 15,00 & 3,75 & 1,88 \\
\hline & Videocassete & 100 & 16,00 & 24,00 & 16,00 & 4,00 & 2,00 \\
\hline & Videogame & 20 & 15,00 & 22,50 & 15,00 & 3,75 & 1,88 \\
\hline
\end{tabular}

Fonte: elaboração a partir de Eletrobras (2007), Coelba (COMPANHIA DE ELETRICIDADE..., 2012), CPFL (COMPANHIA PAULISTA..., 2012), Cemig (COMPANHIA..., 2014), Inmetro (INSTITUTO NACIONAL..., 2020) e Abrahão (2015).

Na determinação do coeficiente $k t$ foi desprezada a participação relativa dos domicílios que não possuem equipamentos "i”, uma vez que não haverá consumo de energia elétrica pelo equipamento nesses domicílios.

Para os equipamentos de ar condicionado, chuveiros, iluminação e carregador de celular, seguem as seguintes considerações, seguindo a metodologia de Abrahão (2015).

Coeficiente kt para equipamentos de ar condicionado - $\mathrm{O}$ coeficiente $k t$ para o equipamento de ar condicionado ponderou a parcela $P u$ para cada nível de clima estabelecido pela pesquisa PPH, sendo esses níveis: quente, frio e ameno.

Coeficiente de ajuste kt do hábito de uso de posição da chave dos chuveiros - O coeficiente de ajuste kt não foi estimado para os chuveiros. Na pesquisa PPH 2004-2006, o hábito de uso $(H u)$ dos chuveiros foi apresentado através do uso em medida relativa à posição da chave do chuveiro para dois períodos, verão e inverno. Este trabalho estimou um coeficiente do hábito de uso para cada período, verão e inverno, expresso respectivamente por ktchv e ktchi. Foi estabelecido o peso adimensional 1 para o período "verão", e 2 para "inverno", referente à relação entre a medida de potência ( $p i, \mathrm{~W})$ em cada uma dessas situações de uso. Os coeficientes ktchv e ktchi, de ajuste do hábito do chuveiro, foram estimados a partir da média ponderada do hábito de uso da chave pelo peso de cada um dos períodos (verão e inverno), e ainda descontada a participação em medida relativa dos chuveiros com uso de chave desligada.

Não houve determinação do coeficiente de ajuste por hábito de uso para os equipamentos iluminação (lâmpadas) e carregador de celular.

Os equipamentos com índice de posse próximo de zero, tais como: fax, projetor de jardim e adega, não foram incluídos no estudo.

\section{Técnica analítica para a estimativa da estrutura de consumo por uso final}

Uma vez criado o painel de dados dos anos 2005 e 2019, foi determinada a estrutura de consumo de energia elétrica por equipamento " $i$ " e por região “ $j "$.

\section{Coeficiente de consumo de energia elétrica por equipamento $\left(c_{i}\right)$}

A Equação 2, utilizada por Abrahão (2015) e adaptada de Silva et al. (2014), apresenta a formulação para a determinação do coeficiente de consumo de energia elétrica por equipamento, exceto para as lâmpadas. 
$c_{i}(W h / m$ ês $)=p_{i}(W) \times t m_{i}(h / m e ̂ s)$

Eq. 2

Onde:

$c$ (Wh/mês) expressa o coeficiente de consumo por equipamento; $i$ expressa o equipamento;

$p(\mathrm{~W})$, a potência do equipamento; $\mathrm{e}$

tm (h/mês), o tempo médio mensal de utilização do equipamento por domicílio.

A Equação 3, utilizada por Achão (2003) e Abrahão (2015), apresenta a determinação do coeficiente de consumo das lâmpadas. Essa formulação considera um fator de uso simultâneo de $65 \%$ das lâmpadas em um domicílio.

$c_{i}(W h / m \hat{e} s)=p_{i}(W) \times t m_{i}(h / m \hat{e} s) \times 0,65$

Eq. 3

Onde:

$c$ (Wh/mês) expressa o coeficiente de consumo por equipamento;

$i$ expressa o equipamento;

$p(\mathrm{~W})$, a potência do equipamento; e

tm (h/mês), o tempo médio mensal de utilização do equipamento por domicílio.

\section{Consumo anual de energia elétrica estimado por equipamento por região $\left(E_{i j}\right.$, $\left.G W h / a n o\right)$}

A Equação 4, adaptada do estudo de Morishita e Ghisi (2010) por Abrahão (2015), apresenta a formulação para a estimativa do consumo de energia elétrica por equipamento e por região, exceto para os chuveiros e para os aparelhos celulares.

$E i j\left(\frac{G W h}{a n o}\right)=\sum_{i ; j}^{n} \frac{\left(c_{i} \times n E D_{i j} \times n D_{j} \times k t_{i j} \times 12\right)}{10^{9}}$

Onde:

$E$ (GWh/ano) expressa o consumo anual estimado de energia elétrica;

$i$ expressa o equipamento;

$j$ expressa a região;

$c$ (Wh/mês) expressa o coeficiente de consumo mensal estimado por equipamento;

$n E D$, o número de equipamento por domicílio;

$n D$, o número de domicílios;

$k t$, o coeficiente de ajuste do tempo médio mensal de uso de equipamentos;

o termo 12 converte o coeficiente de consumo mensal para doze meses anuais; e

o termo $10^{9}$ converte unidades de Wh para GWh.

\section{Chuveiros}

A Equação 5 apresenta a formulação para a estimativa do consumo de energia elétrica para os chuveiros, segundo o estudo de Abrahão (2015).

$E_{i j}(G W h / a n o)=\sum_{i ; j}^{n} \frac{\left[c i x n E D_{i j} x n D_{j} x n P D_{j} x(k t c h v+k t c h i)_{j} \times 12\right]}{10^{9}}$

Onde:

$E(\mathrm{GWh} / \mathrm{ano})$ expressa o consumo anual de energia elétrica estimado para o chuveiro;

$i$ expressa o chuveiro elétrico;

$j$ a região;

$c$ (Wh/mês), o coeficiente de consumo mensal estimado do chuveiro;

$n E D$, o número de chuveiros por domicílio;

$n D$, o número de domicílios; 
$n P D$, o número de pessoas por domicílio;

$k t c h v$ e $k t c h i$, o coeficiente de ajuste do hábito de uso da chave do chuveiro para verão e para inverno respectivamente;

o termo 12 converte o coeficiente de consumo mensal para doze meses anuais; e

o termo $10^{9}$ converte unidades de Wh para GWh.

Para a determinação do consumo de energia elétrica do chuveiro foi considerado $n E D j=1$ para as regiões onde $n E D \geq 1$, uma vez que a quantidade superior a 1 unidade de chuveiro dentro do domicílio não amplia seu uso por pessoa.

\section{Carregadores de aparelhos celulares}

O consumo de energia elétrica estimado para o carregador dos aparelhos de celular foi determinado através da Equação 6, segundo estudo de Abrahão (2015):

$E_{i j}(G W h / a n o)=\sum_{i ; j}^{n} \frac{(c i \times n E D i j \times n D j \times 12)}{10^{9}}$ Eq. 6

Onde:

$E$ (GWh/ano) expressa o consumo anual de energia elétrica estimado;

$i$ expressa o equipamento de carregador de celular;

$j$ a região;

$c$ (Wh/mês), o coeficiente de consumo estimado para o carregador de celular;

$n E D$, o número de carregadores de celular por domicílio;

$n D$, o número de domicílios da região;

o termo 12 converte o coeficiente de consumo mensal para doze meses anuais; e

o termo $10^{9}$ converte unidades de Wh para GWh.

\section{Consumo anual de energia elétrica estimado por região $\left(E T_{j}, G W h / a n o\right)$}

O consumo anual de energia elétrica foi determinado através da Equação 7, segundo o estudo de Abrahão (2015):

$E T_{j}(G W h / a n o)=\sum_{i ; j}^{n} E_{i j}$

Onde:

$E T(\mathrm{GWh} / \mathrm{ano})$ expressa o consumo anual de energia elétrica estimado;

$E$ (GWh/ano), o consumo anual de energia elétrica estimado por equipamento; e

$i$ o equipamento.

\section{Uso final anual de energia elétrica por equipamento por região (UF $\left.{ }_{\mathrm{ij}}, \%\right)$}

A Equação 8, utilizada por Ghisi, Gosch e Lamberts (2007), Morishita e Ghisi (2010), Silva et al. (2014) e Abrahão (2015), apresenta a formulação para o cálculo da distribuição relativa do consumo de energia elétrica calculado por uso final de equipamento e por região.

$U F_{i j}(\%)=\frac{E_{i j}}{\Sigma E T_{j}} \times 100$

Eq. 8

Onde:

$U F(\%)$ expressa o uso final relativo do equipamento por região;

$i$ expressa o equipamento;

$j$ a região;

$E$ (GWh/ano), o consumo anual de energia elétrica estimado por equipamento na região $j$; e

$E T(\mathrm{GWh} / \mathrm{ano})$, o consumo anual de energia elétrica estimado por região. 


\section{Determinação do erro global}

Neste estudo, o erro global foi considerado como o erro acumulado ao longo de todo o processo analítico, supondo, como condição inicial exata, os dados do consumo medido na rede, levantados de EPE (EMPRESA..., 2019, 2020), para os anos 2005 e 2019. A Equação 9 apresenta a formulação, desenvolvida pelos autores, para quantificar o erro global do consumo estimado através da estrutura de uso final (E, GWh), por região, para os anos 2005 e 2019.

$e=\frac{(E j-C j)}{E j} \times 100$

Onde:

$e(\%)$ expressa o erro global do consumo estimado por uso final;

$j$ expressa a região;

E, o consumo anual de energia elétrica estimado por uso final ( $\mathrm{GWh} / \mathrm{ano})$; e

$\mathrm{C}$, o consumo anual de energia elétrica medido na rede ( $\mathrm{GWh} / \mathrm{ano})$.

\section{Resultados e discussões}

\section{Perfil amostral das pesquisas PPH}

Esta seção apresenta de forma sucinta uma análise sobre as características da amostragem de domicílios entrevistados das pesquisas PPH de 2004-2006 e de 2018-2019 para se fazer compreender os limites deste estudo.

As Figuras 2 e 3 apresentam a distribuição regional amostral dos domicílios entrevistados nas pesquisas PPH, segundo os critérios sistemáticos de seleção. Observa-se que na PPH 2004-2006 a seleção amostral de faixas de consumo apresentou homogeneidade espacial, e, ainda, a observação de que, na época, entre 69,0\% e $75,3 \%$ dos domicílios entrevistados apresentavam consumo de até $200 \mathrm{KWh} / \mathrm{mês}$.

A distribuição amostral na PPH 2018-2019 apresentou heterogeneidade espacial regional através do critério de seleção. Nas regiões N e NE, respectivamente 42,0\% e 47,1\% dos domicílios da amostra enquadravam-se nas classes D-E, estimando-se a renda média domiciliar até R\$ 708,19, segundo a Abep (ASSOCIAÇÃO..., 2020).

Figura 2 - Distribuição dos domicílios entrevistados na pesquisa PPH 2004-2006 por faixas de consumo: regiões geográficas (\%)

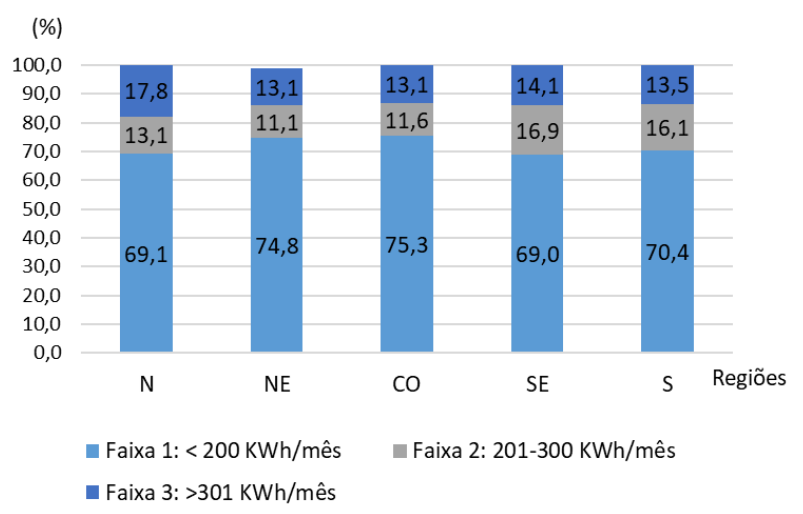

Fonte: elaboração a partir de Eletrobras (2007).

Nota: a metodologia para a classificação do domicílio em relação à classe econômica não foi clarificada na PPH 2018 2019. Estima-se, através do questionário aplicado pela pesquisa, que essa classificação seguiu a metodologia da Abep (ASSOCIAÇÃO..., 2020), que atribui pontos referentes ao grau de instrução do chefe da família, à posse de alguns equipamentos e de veículos, entre outros, para estimar a faixa de renda familiar. 
Figura 3 - Distribuição dos domicílios entrevistados na pesquisa PPH 2018-2019 por classes econômicas: regiões geográficas (\%)

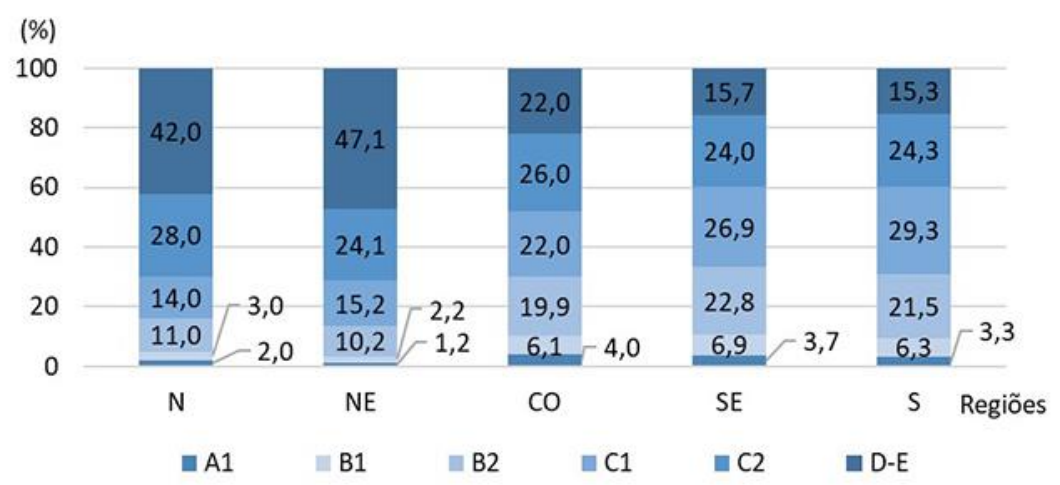

Fonte: elaboração a partir de Eletrobras (2019).

A Figura 4 apresenta a cobertura amostral dos domicílios entrevistados nas PPH 2004-2006 e PPH 20182019 comparada à quantidade total de domicílios existentes por região. Observam-se desproporções entre a quantidade de domicílios entrevistados e a quantidade total de domicílios em cada região nas duas pesquisas, o que pode ter ocorrido em função dos critérios sistemáticos estabelecidos para a construção do mapa amostral na metodologia dessas. Como exemplo, observa-se que 37\% dos domicílios entrevistados na PPH 2004-2006 se localizavam na região SE, e na PPH 2018-2019 56\% desses se localizavam nas regiões N e NE. Nota-se ainda que a relação entre a proporção de domicílios entrevistados e a proporção total de domicílios, na PPH 2004-2006 foi de aproximadamente 2,0 nas regiões $\mathrm{N}$ e CO, e de aproximadamente 1,0 nas regiões CE, SE e S. Já na PPH 2018-2019 essa relação foi de 2,9, 1,2 e 1,6 para as regiões N, NE e CO, respectivamente, e de 0,5 e 0,6 para as regiões $\mathrm{SE}$ e $\mathrm{S}$. Diante do exposto, atenta-se sobre indícios de erros de visibilidade amostral, principalmente na PPH 218-2019.

A amostra da pesquisa PPH 2004-2006 indicou que, em média, 85\% dos domicílios entrevistados eram do tipo casa, com alteração desse índice para 92\% na PPH 2018-2019. Em relação à proporção de domicílios entrevistados relativos à área média construída, houve equivalência entre as duas pesquisas em todas as regiões, exceto na $\mathrm{CO}$. A maioria dos domicílios entrevistados nas pesquisas PPH possuía área construída entre $51 \mathrm{~m}$ e $150 \mathrm{~m}$ quadrados, sendo essa parte equivalente a $60 \%$ na região $\mathrm{N}, 66 \%$ na região $\mathrm{NE}, 51 \%$ na região SE e $86 \%$ na região S. Na região CO esse percentual foi de $86 \%$ na PPH 2004-2006 e de $77 \%$ na PPH 2018-2019.

A Figura 5 apresenta o perfil de consumo médio mensal por classes econômicas do grupo amostral da PPH 2018-2019, por região, estimado a partir de Eletrobras (2019). A maioria das classes econômicas apresentou consumo médio igual ou inferior a $200 \mathrm{KWh} / \mathrm{mês}$, equivalente à faixa 1 da PPH 2004-2006. De forma surpreendente, todas as classes econômicas da região $\mathrm{N}$ apresentaram o consumo médio maior do que as mesmas classes nas outras regiões. Para a classe D-E, o maior indicador de consumo médio mensal foi identificado na região $\mathrm{N}$ e equivalente a $139,92 \mathrm{KWh} / \mathrm{mês}$, e o menor na região $\mathrm{NE}$, correspondendo a 99,49 KWh/mês. A Figura 6 apresenta o consumo médio mensal do conjunto amostral regional da PPH 2018-2019 por classe econômica. Verifica-se o elevado consumo das classes C2 e D-E nas regiões $\mathrm{N}$ e NE, que representaram, respectivamente, $70 \%$ e $71 \%$ dos domicílios totais entrevistados nessas regiões e responsáveis por, respectivamente, $57 \%$ e $60 \%$ do consumo na região. Nas regiões $\mathrm{CO}$, $\mathrm{SE}$ e $\mathrm{S}$, os domicílios das classes $\mathrm{C} 2$ e D-E, que representaram 48\%, 40\% e 40\% respectivamente, dos domicílios totais entrevistados nessas regiões mostraram-se correspondência equivalente a $35 \%, 33 \%$ e $30 \%$ do consumo na região, respectivamente. Dessa forma, observa-se além da diversidade regional, a intensidade do impacto dos domicílios das classes C2 e D-E sobre o consumo nas regiões N e NE.

\section{Estrutura de consumo de energia elétrica por região geográfica}

A Figura 7 apresenta a estrutura de consumo de energia elétrica por uso final estimada, por região geográfica, para os anos 2005 e 2019, a partir da qual conclui-se que a mesma não deve ser discutida em uma abordagem de média nacional, uma vez que houveram diferenças significantes entre as regiões. Essa análise é confirmada pela comparação dos resultados de uso final desagregados regionalmente nos estudos de Almeida, Schaeffer e La Rovere (2001) e de Silva et al. (2014), aos resultados de abrangência nacional 
nos estudos de Almeida, Schaeffer e La Rovere (2001) e de Ghisi, Gosch e Lamberts (2007). Comparando os resultados deste estudo aos resultados de Januzzi e Schipper (1991), Almeida, Schaeffer e La Rovere (2001) e Ghisi, Gosch e Lamberts (2007), referentes a um período anterior ao ano de 2005, observa-se alteração na dinâmica dos usos finais. As maiores alterações nessa comparação foram a redução do uso final da categoria iluminação e a ampliação do uso final das categorias conservação de alimentos e conforto ambiental. Os resultados deste estudo foram concordantes com as observações de Almeida, Schaeffer e La Rovere (2001) referentes a uma maior participação no uso final da categoria conservação de alimentos e a reduzida participação da categoria aquecimento de água na região $\mathrm{N}$.

Figura 4 - Comparação entre o conjunto amostral de domicílios entrevistados nas pesquisas PPH 20042006 e PPH 2018-2019 e o total de domicílios existentes: regiões geográficas (\%)

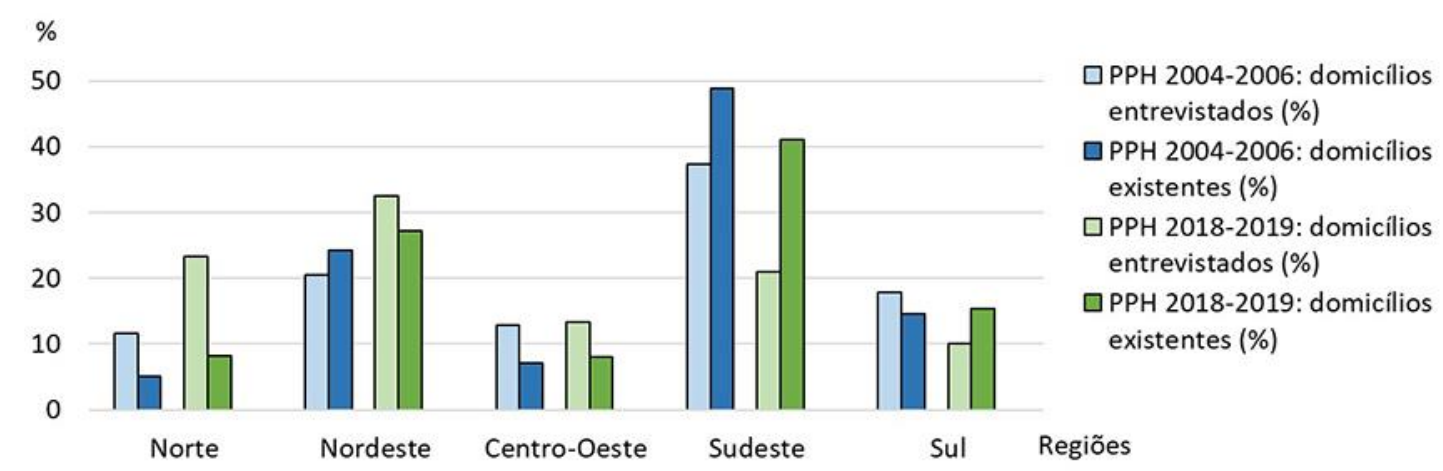

Fonte: elaboração a partir de Eletrobras (2007, 2019).

Figura 5 - Consumo médio mensal dos domicílios entrevistados na pesquisa PPH 2018-2019 por classe econômica: regiões geográficas (\%)

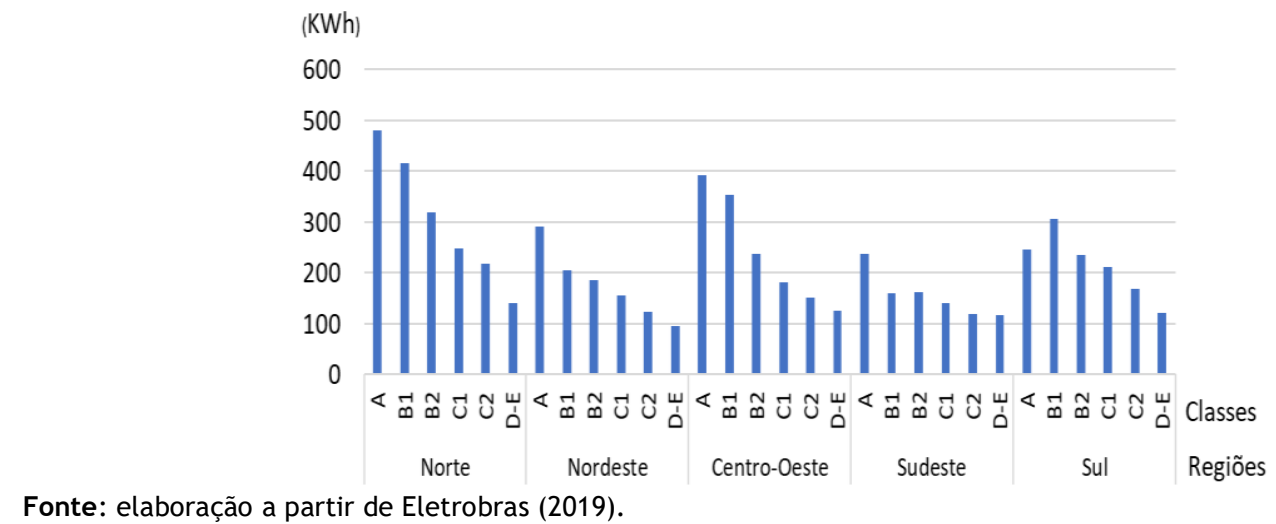

Fonte: elaboração a partir de Eletrobras (2019).

Figura 6 - Consumo médio mensal do conjunto amostral por classe dos domicílios entrevistados na pesquisa PPH 2018-2019 por classes econômicas: regiões geográficas (\%)

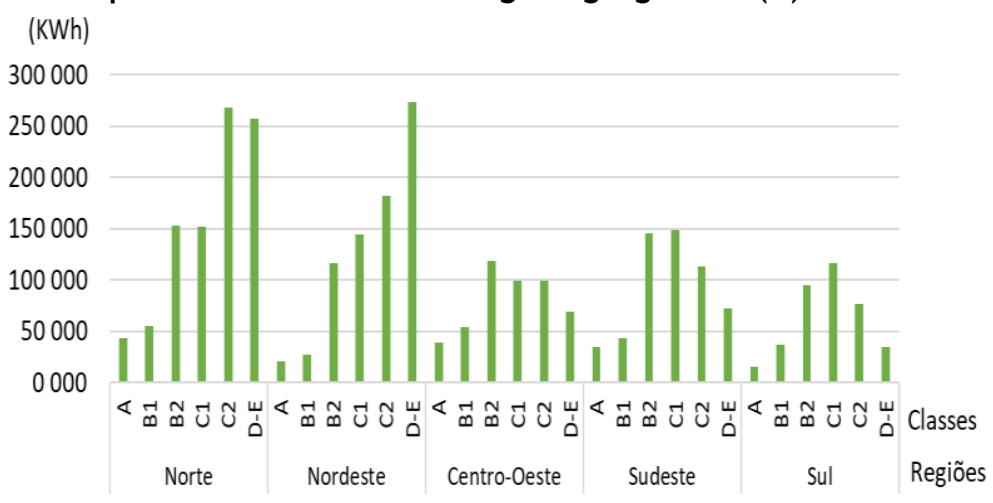

Fonte: elaboração a partir de Eletrobras (2019). 
Os resultados da região $\mathrm{S}$ para as categorias aquecimento de água e conservação de alimentos foram condizentes aos verificados por Silva et al. (2014).

Ademais, houve concordância entre os resultados indicando relevante participação do uso final das categorias conservação de alimentos em todas as regiões, e de aquecimento de água nas regiões CO, SE e S.

De modo geral, a evolução da estrutura de consumo entre os anos 2005 e 2019 apresenta tendência de redução da participação do grupo de conservação de alimentos em virtude do crescimento do consumo das outras categorias. Todas as regiões, exceto a S, apresentaram tendência de redução do uso final da categoria aquecimento de água de 2005 para 2019. É ainda surpreendente que, apesar de observadas mudanças estruturais entre as categorias de consumo por uso final entre as regiões nos dois anos analisados, verifica-se claro predomínio do consumo de equipamentos das categorias conforto ambiental, aquecimento de água e conservação de alimentos, variando entre $82 \%$ e $91 \%$ do consumo total de energia elétrica em cada região.

Os resultados apresentaram a tendência de crescimento moderado no uso final das categorias lazer e serviços gerais entre 2005 e 2019, acreditando-se que esse fenômeno seja devido a uma maior variedade de equipamentos nas análises, e à tendência de ampliação da variedade de equipamentos com serviços de conectividade.

A Tabela 4 apresenta de forma detalhada a estimativa do consumo de energia elétrica por equipamento e por região para os anos 2005 e 2019.

$\mathrm{Na}$ estrutura de 2005 e 2019, o maior consumo identificado nas regiões N, NE e CO refere-se à geladeira, compatível com as análises realizadas do grupo amostral dessas regiões, conferindo espaço para implementação de medidas de eficiência energética para esse tipo de aparelho. O maior consumo na região SE foi o do chuveiro em posição de chave no inverno. Já na região $\mathrm{S}$ o maior consumo em 2005 foi o da geladeira, e em 2019 foi o do chuveiro em posição de chave no inverno.

\section{Figura 7 - Estrutura de consumo residencial de energia elétrica por uso final, por categoria de equipamento, por região geográfica, ano 2005 e ano 2019 (\%)}

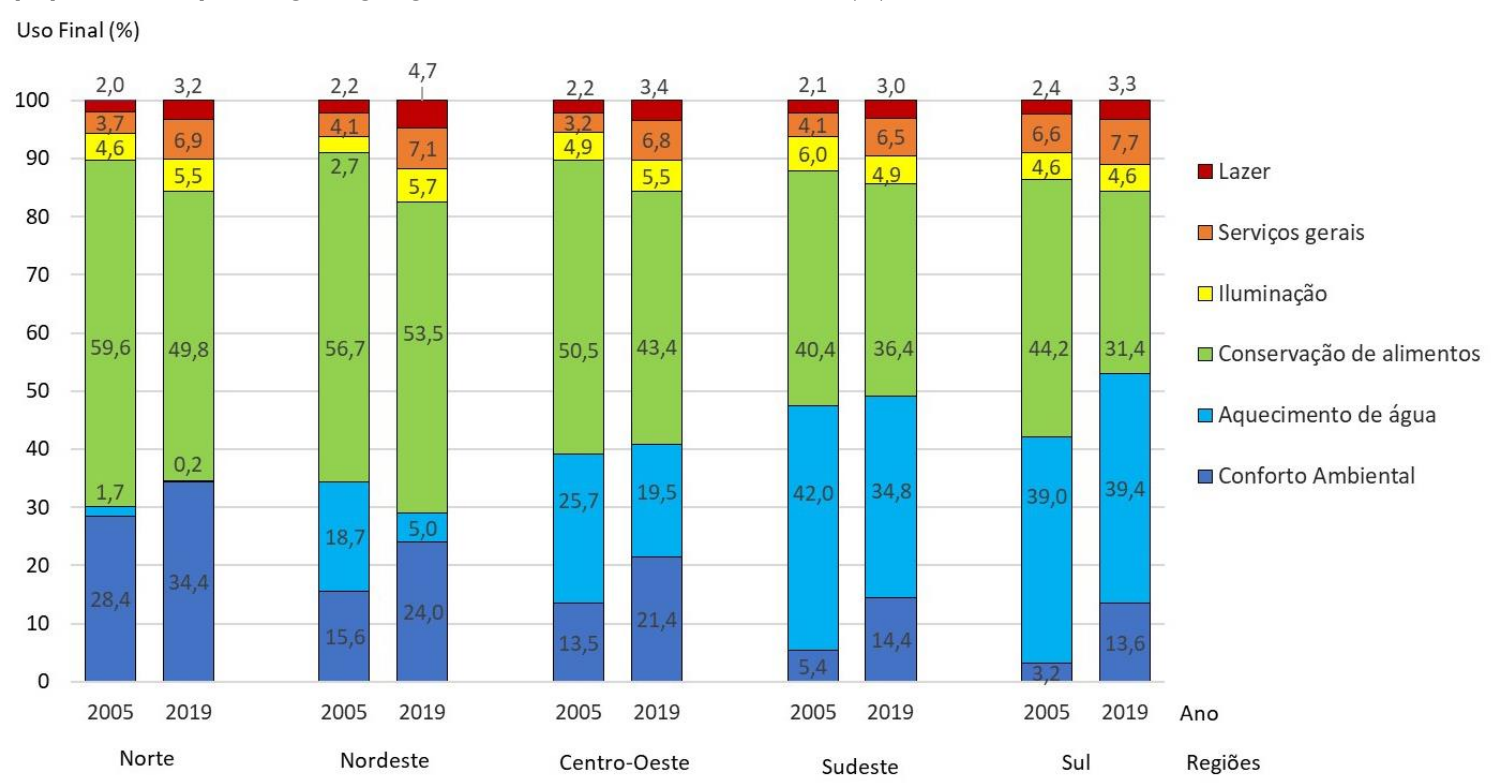


Tabela 4 - Estrutura de consumo residencial de energia elétrica, por equipamento, por região geográfica, ano 2005 e ano 2019 (Ei, GWh/ano) (Continua...)

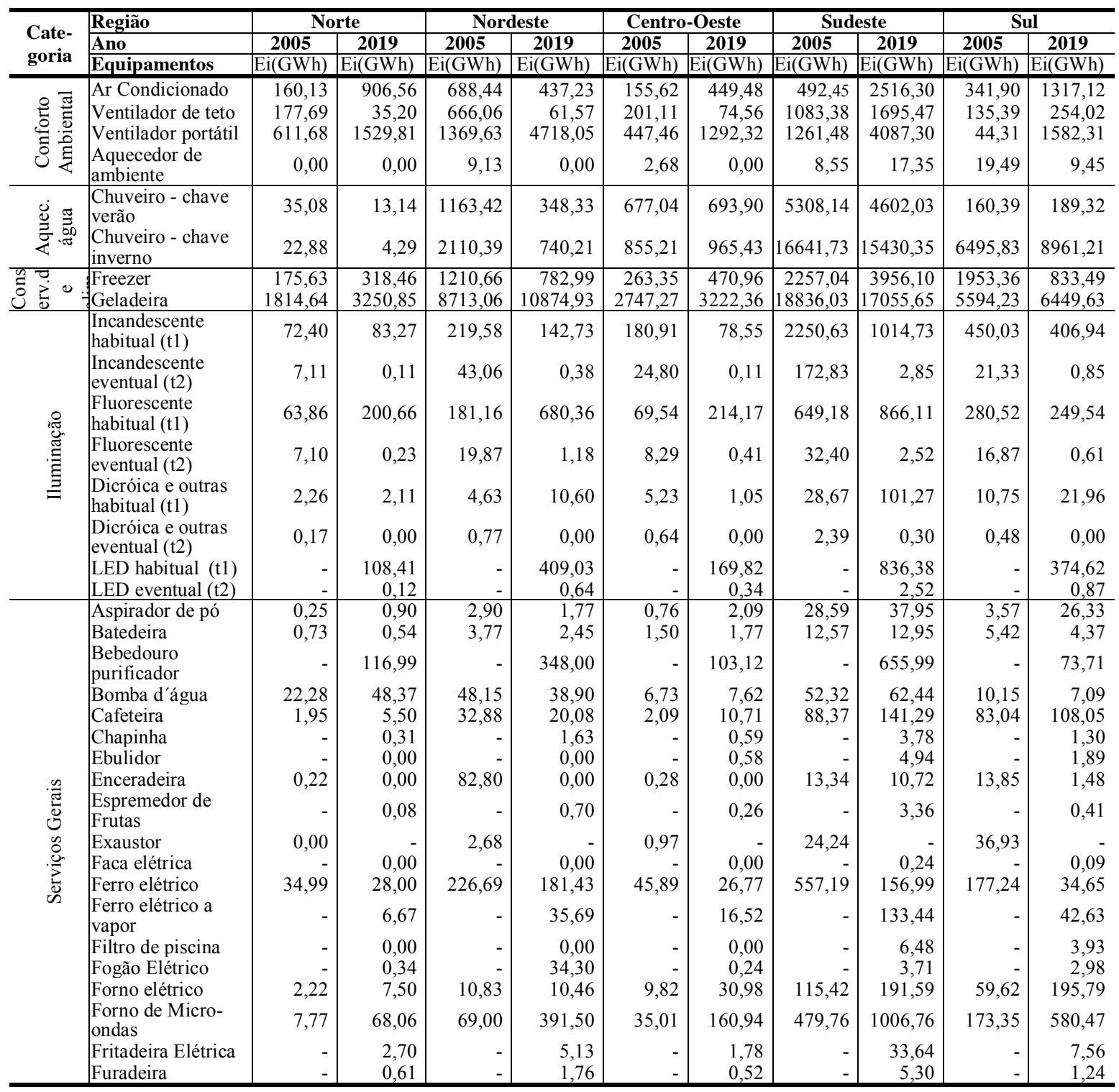

Nota: 1) 0 consumo não apresentado refere-se a equipamentos não contemplados nas pesquisas PPH. 2) Os resultados de equipamentos que apresentaram a medida de consumo equivalente a 0,00 foram influenciados pela falta de posse e/ou pela falta de hábito de uso levantado nos dados das pesquisas $\mathrm{PPH}$. 
Tabela 4 - Estrutura de consumo residencial de energia elétrica, por equipamento, por região geográfica, ano 2005 e ano 2019 (Ei, GWh/ano) (...continuação)

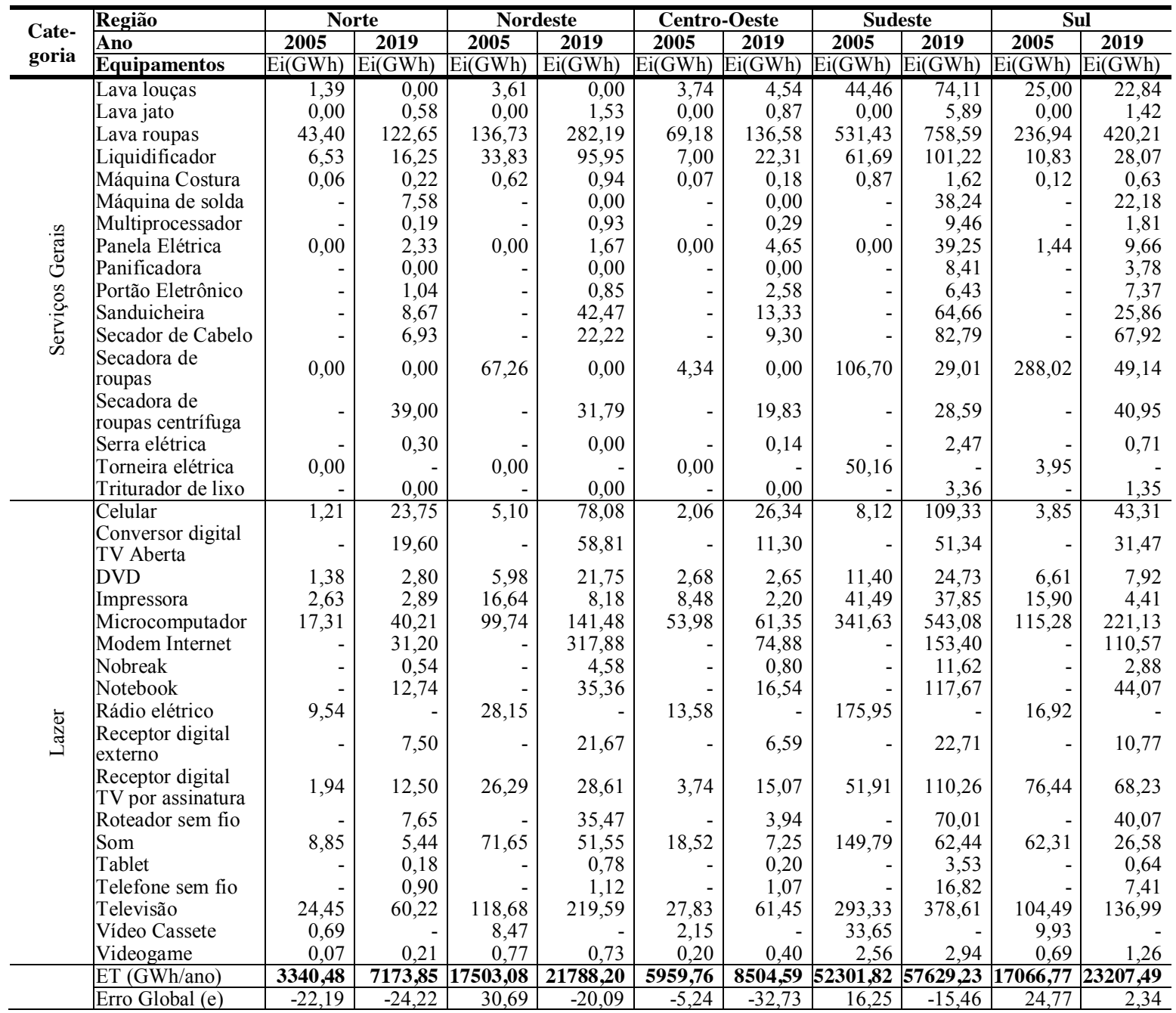

Nota: 1) 0 consumo não apresentado refere-se a equipamentos não contemplados nas pesquisas PPH. 2) Os resultados de equipamentos que apresentaram a medida de consumo equivalente a 0,00 foram influenciados pela falta de posse e/ou pela falta de hábito de uso levantado nos dados das pesquisas PPH.

Para uma melhor compreensão, as análises dos resultados apresentadas a seguir foram elaboradas por categoria de equipamentos.

Conforto Ambiental - A categoria conforto ambiental apresentou relevante crescimento entre 2005 e 2019 , principalmente nas regiões SE e S. Em 2015 e 2019, o maior consumo dessa categoria foi identificado nas regiões NE e SE. Houve crescimento do consumo de ar condicionado de 3 a 6 vezes entre 2005 e 2019 , exceto na região NE. Já o consumo dos ventiladores dobrou em todas as regiões, exceto na região $\mathrm{S}$ onde cresceu aproximadamente 10 vezes. $\mathrm{O}$ uso do ar-condicionado apresentou maior frequência nos domicílios principalmente no período noturno, entre 19h e 7h (ELETROBRAS, 2019). Nas regiões de clima quente, como $\mathrm{N}$ e NE, a utilização do ar-condicionado ocorreu ao longo de todo o ano, denotando que os modelos habitacionais nessas regiões devem atender a altos padrões de desempenho térmico, de forma a propiciar a diminuição do número de horas necessárias para condicionamento artificial do ar. Acredita-se que as condições econômicas dos domić́lios inseridos em classes de menor renda e localizados nas regiões de clima quente, como $\mathrm{N}$ e $\mathrm{NE}$, ainda limitam a posse e o grau de utilização do equipamento de ar condicionado, o que confere estimar potenciais para implementação de políticas de incentivo visando a maior eficiência energética. Na região NE houve redução do consumo do ar-condicionado devido à redução do índice de posse, o que pode estar mais relacionado à metodologia de determinação da condição sistemática amostral nessa região entre as duas pesquisas, à uma tendência de descarte e/ou redução de compra desses equipamentos. Nas demais regiões observou-se a intensificação do uso desse equipamento no 
verão (ELETROBRAS, 2019). Nesse sentido, é relevante a consideração da introdução da métrica sazonal e de níveis de consumo mais restritivos para etiquetagem de eficiência energética dos equipamentos de ar condicionado, conforme indicado por Costa et al. (2019) e por Projeto Kigali (2019). Ademais, é surpreendente que, para os domicílios com posse do ar-condicionado, o número de horas de utilização desse apresente pequena variação entre as classes econômicas (ELETROBRAS, 2019), o que pode estar relacionado aos estímulos das políticas para redução da pobreza e para a ampliação da qualidade de vida, como a distribuição de renda, a redução de déficit, a facilidade de crédito e os juros reduzidos no mercado, políticas essas que conformam um cenário favorável à ampliação da posse desse equipamento.

Aquecimento de Água - O grupo de aquecimento de água apresentou redução na participação de consumo em todas as regiões entre 2005 e 2019, exceto nas regiões CO e S. Como esperado e devido ao clima quente, o grupo de aquecimento de água na região $\mathrm{N}$ manteve participação insignificante no uso final nos períodos analisados. Apesar do menor uso final dessa categoria nas regiões N e NE, a pesquisa PPH 2018-2019 apresenta que houve intensificação do uso do chuveiro elétrico com a temperatura máxima nos meses de maio a agosto, independentemente da classe econômica (ELETROBRAS, 2019). De forma geral, os resultados de uso final do consumo de energia elétrica para o aquecimento de água indicam que programas e incentivos ao uso de sistema solar de aquecimento de água podem ser intensificados, principalmente nas regiões SE e S, que apresentaram elevada magnitude do consumo em 2019, condizente com a PPH 20182019, que aponta que apenas $0,96 \%$ dos domicílios, em média, possuem sistema solar para aquecimento de água (ELETROBRAS, 2019).

Conservação de Alimentos - A elevada participação da categoria conservação de alimentos, já identificada nos estudos de uso final de Januzzi e Schipper (1991), Almeida, Schafffer e La Rovere (2001) e Ghisi, Gosch e Lamberts (2007), permaneceu na estimativa da estrutura de consumo dos anos 2005 e 2019, sendo função do número de domicílios, e não dependente do número de pessoas no domicílio. Observou-se o crescimento do consumo do freezer e da geladeira entre 2005 e 2019 em todas as regiões, exceto no consumo do freezer nas regiões NE e S, e da geladeira na região Sudeste. Dada a universalização da posse da geladeira, o incremento da ordem de 13 milhões de domicílios nas regiões NE e SE contribuíram para manter a elevada participação de uso final dessa categoria, além de se apresentarem como as regiões de maior consumo nessa categoria em 2019. O crescimento do consumo está relacionado ao incremento do número de domicílios, promovido principalmente pela melhoria de renda através de programas de distribuição de renda, como o Bolsa Família, que concentrou 47\% dos benefícios às famílias da região NE (BRASIL, 2004). Apesar da introdução de geladeiras com níveis de consumo mais eficientes, o mercado vem oferecendo modelos com maior volume de refrigeração, logo desacelerando a redução do consumo esperada para essa categoria. Do ponto de vista da disseminação de equipamentos com melhores índices de eficiência energética, é esperada, ao longo dos anos em todas as regiões, uma desaceleração do consumo absoluto desse grupo, mantendo-se, no entanto, pouca redução na participação de uso final devido à associação do elevado índice de posse, da elevada potência, das intensas horas diárias de uso, e em função da dependência do número de domicílios, em crescimento.

Iluminação - A participação do consumo por uso final para iluminação entre 2005 e 2019 variou entre 2,7\% e $6,0 \%$, havendo ainda aumento do consumo de 1,5 a 3 vezes em todas as regiões, exceto na região SE. Nessa categoria, as regiões SE e NE apresentaram maior consumo em 2019. Entre 2005 e 2019 verificou-se redução de $50 \%$ do consumo das lâmpadas incandescentes em todas as regiões, exceto nas regiões $\mathrm{N}$ e $\mathrm{S}$. Em 2005 o consumo das lâmpadas incandescentes apresentou-se superior ao consumo das fluorescentes em todas as regiões, com inversão dessa relação em 2019, exceto na região S. O consumo das lâmpadas LED foram maiores nas regiões NE, SE e S. Esse resultado indica que as previsões feitas de uma entrada significativa da iluminação LED no setor após 2016, quando finalizados os prazos de escoamento da fabricação, importação e comercialização dessas no mercado nacional, não se comprovaram. Isso pode ser ratificado pela verificação de que em 2019 o índice de posse das lâmpadas LED ainda era é inferior aos índices de posse de lâmpadas incandescentes e fluorescentes juntas, o que denota um relevante espaço para implementação e incentivos para a substituição destas nos domicílios.

Serviços Gerais - A ampliação da qualidade de vida, as mudanças sociais vivenciadas no país e a existência de um cenário econômico favorável facilitaram a introdução no domicílio de novas modalidades de eletrodomésticos que prestam serviços às pessoas, auxiliando e reduzindo o tempo dedicado às tarefas domésticas. Entre 2005 e 2019 os equipamentos da categoria serviços gerais, também função do número de domicílios, apresentou crescimento do uso final. A análise do grau de utilização desses equipamentos no domicílio indicou que os índices de posse nem sempre estão associados a um alto consumo, uma vez que se verificou um grau de utilização bastante diversificado entre as regiões. Por exemplo, a lava-roupas na região 
$\mathrm{N}$ possui posse superior à região $\mathrm{NE}$, no entanto o grau de utilização na região $\mathrm{N}$ é inferior à $\mathrm{NE}$, resultando em menor consumo. O bebedouro purificador, por operar continuamente conectado à rede elétrica, apresentou consumo relevante, apesar de um baixo índice de posse. A cultura do preparo de alimentos também influencia o consumo, como indicam as análises de posse e grau de utilização da panela elétrica, da cafeteira e do forno de micro-ondas. A posse de panela elétrica é maior na região CO do que nas regiões SE e $\mathrm{S}$, mas os graus de utilização nessas últimas regiões são superiores ao da $\mathrm{CO}$, principalmente na região $\mathrm{SE}$, resultando em um consumo superior. As regiões SE e $\mathrm{S}$ apresentam elevados índices de posse e de graus de utilização do forno de micro-ondas. Já na região $\mathrm{NE}$ a posse do forno de micro-ondas é inferior à da $\mathrm{CO}$, no entanto possui grau de utilização muito superior ao da região CO. O consumo da bomba d'água apresenta baixo índice de posse, apesar de a maioria dos domicílios entrevistados ser casas, logo estimando-se uma pequena posse de caixas d'água na amostra de domicílios e seu carregamento por pressão, diretamente da rede pública. O ferro elétrico apresentou redução do índice de posse entre as pesquisas PPH de 2004-2006 e de 2018-2019, levando à redução nos resultados de consumo. Acredita-se que essa redução está relacionada às diferentes metodologias de seleção de domicílios do mapa amostral. De forma geral, os equipamentos de maior consumo em 2019 foram o forno de micro-ondas, a lava-roupas e o bebedouro purificador. As regiões NE, SE, e S apresentaram maior consumo de equipamentos dessa categoria em 2019.

Lazer - A categoria lazer foi a que apresentou menor dinâmica de crescimento do uso final em relação as demais categorias, variando em 2005 de 2,0\% a 2,4\%, e em 2019 de 3,0\% a 4,7\%. Os equipamentos de maior consumo em 2019 foram o microcomputador, o modem de internet e a televisão, com maior consumo nas regiões $\mathrm{SE}, \mathrm{NE}$ e $\mathrm{S}$. O aumento da posse de equipamentos dessa categoria e de sua variedade se deve à introdução de novas tecnologias e de modalidades de dispositivos, associados aos cenários econômicos e à cultura da conectividade.

De forma geral, as análises levam a crer que o setor residencial apresenta elevado potencial para implementação de medidas de eficiência energética, no entanto é imprescindível que o padrão de consumo regional seja considerado para que os resultados sejam mais efetivos.

\section{Erro global}

O erro global estimado neste estudo, apresentado na Tabela 4, considerou o consumo de energia elétrica medido na rede como uma condição exata. O erro global considerou a soma dos erros aleatórios importados junto aos dados das pesquisas $\mathrm{PPH}$, bem como os erros dos processos da técnica analítica desenvolvida neste estudo, logo foi interpretado como a diferença entre o consumo estimado através da estrutura de uso final e o consumo medido na rede para os anos 2005 e 2019, por região geográfica. Os resultados da região NE apresentaram maior amplitude de erro global, enquanto os resultados de 2005 da região $\mathrm{CO}$, e da região $\mathrm{S}$ em 2019 apresentaram erros de menor magnitude. Considera-se ainda que os erros não diminuem a integridade da metodologia desenvolvida e das análises apresentadas.

\section{Conclusão}

Este trabalho estimou o consumo de energia elétrica do setor residencial por uso final desagregado por região geográfica para os anos 2005 e 2019. A relevância deste estudo está no preenchimento da lacuna da determinação de cenários de uso final para esses anos. A metodologia para o desenvolvimento do estudo utilizou como base os dados das pesquisas PPH dos anos 2004-2006 e 2018-2019 (ELETROBRAS, 2007, 2019).

Pôde-se verificar que a estrutura de consumo por uso final modificou-se ao longo dos anos. Conhecer essa evolução contempla o reconhecimento dos equipamentos ou categorias de equipamentos com maior consumo, resultados que podem servir a futuras pesquisas e contribuir para a evolução das políticas energéticas. A metodologia e os resultados deste trabalho permitem um conhecimento geral da distribuição de consumo de energia elétrica do setor residencial segundo seus usos finais, porém não expressam as desigualdades constantes no consumo dos domicílios. O detalhamento do consumo por equipamento e por região geográfica será útil em análises de futuros trabalhos, principalmente quando relacionados ao contexto de eficiência energética de equipamentos.

O consumo de energia elétrica do setor residencial brasileiro estimado para o ano 2019 mostrou um crescimento significativo em todas as regiões, sendo considerados alguns dos motivos: a expansão do acesso à energia elétrica, a ampliação do número de domicílios e a mudança de cultura com a ampliação da posse e de modalidades de equipamentos por domicílio, entre outros. 
A estrutura regional se mostrou dinâmica, o que indica que a análise de consumo médio para o Brasil pode não retratar as singularidades regionais. Nesse sentido, indica-se que um detalhamento regional para as políticas energéticas poderia potencializar os resultados, especialmente no que tange aos sistemas de aquecimento de água e ao uso de aparelhos de ar condicionado, esse último em franca expansão no país.

Como limitações deste estudo, acredita-se que os resultados apresentaram forte relação com os índices de posse média e com o grau de utilização de eletrodomésticos, contemplados nas pesquisas PPH, e com a distribuição regional de domicílios, resultante dos critérios metodológicos para a seleção amostral. Nesse sentido, as condições de classe de consumo e de renda, não desagregadas neste estudo, limitam os resultados. Outra limitação é em função da estimativa do tempo médio de uso dos equipamentos, que afeta diretamente o consumo de energia elétrica.

A elaboração da estrutura de uso final e de consumo de energia elétrica do setor residencial é uma tarefa complexa devido à variedade de fatores que devem ser considerados. Considera-se que a maior dificuldade nessa tarefa é conseguir realizar um levantamento de dados confiáveis com abordagem sobre a posse e o hábito de uso, dentro da amplitude populacional e do número de domicílios do país. Nesse sentido, reconhece-se a relevância da continuidade da pesquisa Posse e Hábitos de Uso de Equipamentos Elétricos na Classe Residencial (PPH) nos próximos anos. As diferenças entre as previsões feitas para a evolução do consumo por uso final entre 2005 e 2019 e as tendências efetivamente apontadas neste estudo indicam que pesquisas desse tipo devem ser feitas em prazos menores ao realizado (12 anos) devido à intensa dinâmica de mudança do uso de energia elétrica no setor residencial.

\section{Referências}

ABRAHÃO, K. C. F. J. Avaliação dos pesos regionais do RTQ-R a partir da análise da estrutura do consumo residencial de energia elétrica por região geográfica. Belo Horizonte, 2015. 244 f. Dissertação (Mestrado em Arquitetura e Urbanismo) - Programa de Pós-Graduação em Ambiente Construído e Patrimônio Sustentável, Universidade Federal de Minas Gerais, Belo Horizonte, 2015.

ACHÃO, C. C. Análise da estrutura de consumo de energia pelo setor residencial brasileiro. Rio de Janeiro, 2003. Tese (Doutorado em Engenharia Civil) - Universidade Federal do Rio de Janeiro, Rio de Janeiro, 2003.

ACHÃO, C. C. L.; SCHAEFFER, R. Decomposition analysis of the variations in residential electricity consumption in Brazil for the 1980-2007 period: measuring the activity, intensity and structure effects. Energy Policy, v. 37, p. 5208-5220, 2009.

AGÊNCIA NACIONAL DE ENERGIA ELÉTRICA. Tarifa social de energia elétrica. Disponível em: https://www.aneel.gov.br/tarifa-social-baixa-renda. Acesso em: 5 dez. 2019.

ALBRECHT, C. F. et al. International transdisciplinary approach to sustainability research related to place: sustainable, affordable homes and ecosystem services in the U.S. and Brazil. In: LEAL FILHO, W.; TORTATO, U.; FRANKENBERGER, F. (ed.). Universities and sustainable communities: meeting the goals of the Agenda 2030. Cham: Springer, 2020. World Sustainability Series.

ALMEIDA, M. A.; SCHAEFFER, R.; LA ROVERE, E. L. The potential for electricity conservation and peak load reduction in the residential sector of Brazil. Energy, v. 26, n. 4, p. 413-429, 2001.

ANDRADE, T. A.; LOBÃO, W. J. A. Elasticidade renda e preço da demanda residencial de energia elétrica no Brasil. Rio de Janeiro: Instituto de Pesquisa Econômica Aplicada, 1997. Texto para Discussão n. 489.

ASSOCIAÇÃO DE EMPRESAS DE PESQUISA. Critério de classificação econômica Brasil - 2018. Disponível em: http://www.abep.org/criterio-brasil. Acesso em: 8 abr. 2020.

BANCO CENTRAL DO BRASIL. Histórico de taxa de juros. Disponível em: https://www.bcb.gov.br/controleinflacao/historicotaxasjuros. Acesso em: 5 nov. 2019.

BANCO INDUSVAL \& PARTNERS. Evolução do crédito no Brasil como \% do PIB (2000-2013). Disponível em: http://www.bip.b.br/port/ri/infofinan/credito.asp. Acesso em: 10 mar. 2014.

BARBOSA, A. L. N. H. Participação feminina na força de trabalho brasileira: evolução e determinantes. In: CAMARANO, A. A. (org). Novo regime demográfico: uma nova relação entre população e desenvolvimento? Rio de Janeiro: Ipea, 2014. 
BORTOLI, K. C. R. de; VILLA, S. B. Adequação ambiental como atributo facilitador da resiliência no ambiente construído em Habitações de Interesse Social. Ambiente Construído, Porto Alegre, v. 20, n. 1, p. 391-422, jan./mar. 2020.

BRASIL. Boletim mensal sobre os subsídios da União - Programa Minha Casa Minha Vida. Ministério da Economia, Edição 10, agosto de 2019. Disponível em: http://www.economia.gov.br/central-deconteudos/publicacoes/boletim-subsidios/arquivos/2019/boletim-mensal-sobre-os-subsidios-da-uniao-2013programa-minha-casa-minha-vida-edicao-10.pdf. Acesso em: 7 nov. 2019.

BRASIL. Casa Civil. Subchefia para Assuntos Jurídicos. Decreto de 2 de dezembro de 1999 - Programa Nacional de Eletrificação Rural " Luz no Campo". Brasília, 1999. Disponível em: http://www.planalto.gov.br/ccivil_03/dnn/anterior\%20a\%202000/1999/Dnn8715.htm. Acesso em: 15 jul. 2019.

BRASIL. Casa Civil. Subchefia para Assuntos Jurídicos. Decreto no 5.209, de 17 de setembro de 2004 Programa Bolsa Família. Brasília, 2004. Disponível em: http:/www.planalto.gov.br/ccivil_03/_Ato20042006/2004/Decreto/D5209.htm. Acesso em: 15 jul. 2019.

BRASIL. Casa Civil. Subchefia para Assuntos Jurídicos. Lei no 10.295, de 17 de outubro de 2001 Política Nacional de Conservação e Uso Racional de Energia. Brasília, 2001. Disponível em: http://www.planalto.gov.br/ccivil_03/LEIS/LEIS_2001/L10295.htm\#art2. Acesso em: 15 jul. 2019.

BRASIL. Casa Civil. Subchefia para Assuntos Jurídicos. Lei no 10.438, de 26 de abril de 2002 Universalização de energia elétrica e outros. Brasília, 2002. Disponível em: http://www.planalto.gov.br/ccivil_03/leis/2002/L10438.htm. Acesso em: 24 jul. 2019.

BRASIL. Casa Civil. Subchefia para Assuntos Jurídicos. Lei no 11.977, de 7 de julho de 2009 - Programa Minha Casa Minha Vida. Brasília, 2009. Disponível em: http://www.planalto.gov.br/ccivil_03/_ato20072010/2009/lei/11 1977.htm. Acesso em: 24 jan. 2019.

BRASIL. Casa Civil. Subchefia para Assuntos Jurídicos. Lei no 12.212, de 20 de janeiro de 2010 - Dispõe sobre a Tarifa Social de Energia Elétrica. Brasília, 2010. Disponível em: http://www.planalto.gov.br/ccivil_03/_Ato2007-2010/2010/Lei/L12212.htm. Acesso em: 24 jan. 2019.

COMPANHIA DE ELETRICIDADE DO ESTADO DA BAHIA. Fornecimento de energia em tensão secundária de distribuição a edificações individuais. 11. ed. Salvador, ago. 2012.

COMPANHIA ENERGÉTICA DE MINAS GERAIS. Simulador de consumo. 2014. Disponível em: http://www.cemig.com.br/pt-br/atendimento/Documents/SimuladorDeConsumo/Cemig\%20\%20Estime\%20seu\%20Consumo2.htm. Acesso em: 28 ago. 2014.

COMPANHIA PAULISTA FORÇA E LUZ. Norma técnica: fornecimento em tensão primária $15 \mathrm{kV}, 25$ $\mathrm{kV}, 34,5$ kV Manual volume 2, set. 2012. Rev. 04/03/2020. Disponível em: http://sites.cpfl.com.br/documentos-tecnicos/GED-2856.pdf. Acesso em: 28 ago. 2014.

COSTA, F. et al. Estudo de impacto regulatório: diretrizes gerais e estudo de caso para condicionadores de ar tipo split system no Brasil. Projeto Kigali, Instituto Clima e Sociedade, Rio de Janeiro, mar. 2019. Disponível em: http://kigali.org.br/publicacoes/. Acesso em: 16 fev. 2020.

DATASEBRAE. Programas sociais: Bolsa Família. Famílias beneficiadas por estado. 2016. Disponível em: https://datasebrae.com.br/programas-sociais/\#estados. Acesso em: 5 nov. 2019.

ELETROBRAS. Pesquisa de posse de eletrodomésticos e hábitos de consumo: ano-base 1987, classe residencial. Rio de Janeiro, 1988.

ELETROBRAS. Pesquisa de posse de eletrodomésticos e hábitos de consumo: 1997-1998: classe residencial. Rio de Janeiro: Eletrobras, Procel, PUC-Rio, 1998.

ELETROBRAS. Pesquisa de posse de equipamentos e hábitos de uso: ano-base 2005 - Classe Residencial. Rio de Janeiro: Eletrobras, Procel, 2007.

ELETROBRAS. Pesquisa de posse e hábitos de uso de equipamentos elétricos na classe residencial. Relatório Técnico, 2019. Eletrobras, Procel, 2019. Disponível em: https://eletrobras.com/pt/AreasdeAtuacao. Acesso em: 23 nov. 2019.

EMPRESA DE PESQUISA ENERGÉTICA. Balanço Energético Nacional 2020: ano base 2019. Disponível em: http://www.epe.gov.br/pt/publicacoes-dados-abertos/publicacoes/balanco-energeticonacional-2020. Acesso em: 29 dez. 2020. 
EMPRESA DE PESQUISA ENERGÉTICA. Consumo Mensal de Energia Elétrica por Classe (regiões e subsistemas) - tabela Mercado Mensal 2004-2018: consumo mensal de energia elétrica por classe, Brasil e regiões. Disponível em: http://www.epe.gov.br/pt/publicacoes-dados-abertos/publicacoes/consumo-deenergia-eletrica. Acesso em: 15 dez. 2019.

ESTIRI, H.; ZAGHENI, E. Age matters: ageing and household energy demand in the United States. Energy Research and Social Science, v. 5, p. 62-70, 2019.

FERREIRA NETO, A. B.; CORRÊA, W. L. R.; PEROBELLI, F. S. Consumo de energia e crescimento econômico: uma análise do Brasil no período 1970-2009. Análise Econômica, v. 34, n. 65, p. 181-204, set. 2019.

GHISI, E.; GOSCH, S.; LAMBERTS, R. Electricity end-uses in the residential sector of Brazil. Energy Policy, v. 35, n. 8, p. 789-202, 2007.

GUO, Z. et al. Residential electricity consumption behavior: influencing factors, related theories and intervention strategies. Renewable and Sustainable Energy Reviews, v. 81, p. 399-412, 2018.

INSTITUTO BRASILEIRO DE GEOGRAFIA E ESTATÍSTICA. Pesquisa nacional por amostra de domicílios anual - grandes regiões: planilhas para download. Rio de Janeiro, 2019. Disponível em: https://www.ibge.gov.br/estatisticas/sociais/rendimento-despesa-e-consumo/9127-pesquisa-nacional-poramostra-de-domicilios.html?=\&t=downloads. Acesso em: 5 dez. 2019.

INSTITUTO BRASILEIRO DE GEOGRAFIA E ESTATÍSTICA. Síntese de indicadores sociais: ano-base 2003. Estudos e pesquisas. Informação demográfica e socioeconômica. Rio de Janeiro, 2004.

INSTITUTO BRASILEIRO DE GEOGRAFIA E ESTATÍSTICA. Síntese de indicadores sociais: ano-base 2005. Estudos e Pesquisas. Rio de Janeiro, 2006. Informação demográfica e Socioeconômica.

INSTITUTO BRASILEIRO DE GEOGRAFIA E ESTATÍSTICA. Síntese de indicadores sociais: uma análise das condições de vida da população brasileira 2013. Rio de Janeiro, 2014a. Disponível em: https://www.ibge.gov.br/estatisticas-novoportal/sociais/educacao/9221-sintese-de-indicadoressociais.html?edicao=17068\&t=publicacoes). Acesso em: 23 dez. 2019.

INSTITUTO BRASILEIRO DE GEOGRAFIA E ESTATÍSTICA. Sistema de contas regionais: Tabela 1 Produto Interno Bruto (valores correntes) - Brasil, Grandes Regiões e Unidades da Federação - 2010-2017. Rio de Janeiro, 2018. Disponível em: https://www.ibge.gov.br/estatisticas/economicas/contasnacionais/9054-contas-regionais-do-brasil.html?=\&t=resultados. Acesso em: 23 dez. 2019.

INSTITUTO BRASILEIRO DE GEOGRAFIA E ESTATÍSTICA. Sistema de Recuperação Automática (SIDRA). Rio de Janeiro, 2014b. Disponível em:

http://www.sidra.ibge.gov.br/bda/tabela/listabl.asp?c=3463\&z=p\&o=18. Acesso em: 22 abr. 2016.

INSTITUTO NACIONAL DE METROLOGIA, NORMALIZAÇÃO E QUALIDADE INDUSTRIAL. Tabelas de consumo: eficiência energética. Disponível em: http://www.inmetro.gov.br/consumidor/tabelas.asp. Acesso em: 05 nov. 2020.

IQBAL, M. N.; KUTT, L.; ROSIN, A. Complexities associated with modeling of residential electricity consumption. In: INTERNATIONAL SCIENTIFIC CONFERENCE ON POWER AND ELECTRICAL ENGINEERING OF RIGA TECHNICAL UNIVERSITY, 59., Riga, 2018. Proceedings [...] Riga, 2018.

IRFFI, G. et al. Previsão da demanda por energia elétrica para classes de consumo da região Nordeste, usando OLS dinâmico e mudança de regime. Economia Aplicada, v. 13, n. 1, p. 69-98, 2009.

JANUZZI, G. M.; SCHIPPER, L. The structure of electricity demand in the Brazilian household sector. Energy Policy, v. 19, n. 11, p. 879-891, 1991.

JONES, R. V.; FUERTES, A.; LOMAS, K. J. The socio-economic, dwelling and appliance related factors affecting electricity consumption in domestic buildings. Renewable and Sustainable Energy Reviews, v. 43, p. 901-917, 2015.

KEMFERT, C. Applied economic-environment-energy modeling for quantitative impact assessment. International Centre for Integrated assessment and Sustainable development (ICIS). Puzzle-solving for policy II. 2005.

LIDDLE, B. Consumption-driven environmental impact and age structure change in OECD Countries.

Demographic Research, v. 24, p. 749-770, 2011. 
LIDDLE, B. Impact of population, age structure, and urbanization on carbon emissions/energy consumption: evidence from macro-level, cross-country analyses. Population Environmental, v. 35, n. 3, p. 286-304, 2014.

MATTOS, L. B.; LIMA, J. E. Demanda residencial de energia elétrica em Minas Gerais: 1970-2002. Nova Economia, v. 15, n. 3, p. 31-52, set./dez. 2005.

MODIANO, E. M. Elasticidade-renda e preços da demanda de energia elétrica no Brasil. Rio de Janeiro: Departamento de Economia PUC/RJ, 1984. Texto para discussão n. 68,

MOREIRA, V. S.; SILVEIRA, S. F. R.; EUCLYDES, F. M. Minha Casa, Minha Vida em números: quais conclusões podemos extrair? In: ENCONTRO BRASILEIRO DE ADMINISTRAÇÃO PÚBLICA, 4., João Pessoa, 2017. Anais [...] João Pessoa, 2017.

MORISHITA, C.; GHISI, E. Assessment of the impact of energy-efficiency household appliances on the electricity consumption in the residential sector of Brazil. In: WORLD ENERGY COUNCIL CONGRESS, Montreal, 2010. Proceedings [...] Montreal: World Energy Council Congress, 2010.

OLIVEIRA, A.; SILVEIRA, G. B.; BRAGA, J. M. Diversidade sazonal do consumo de energia elétrica no Brasil. Pesquisa Planejamento Econômico, v. 30, n. 2, p. 211-257, ago. 2000.

OLIVEIRA, M. H. F.; REBELATTO, D. A. N. The evaluation of electric energy consumption in the Brazilian residential sector: a technological improvement proposal in order to increase its efficiency. Renewable and Sustainable Energy Reviews, v. 49, p. 836-844, 2015.

PROJETO KIGALI. Caminhos para a eficiência energética no mercado brasileiro de condicionadores de ar: principais resultados. Rio de Janeiro, 2019. Disponível em: http://kigali.org.br/publicacoes/. Acesso em: 16 fev. 2020.

SCHAEFFER, R. et al. Energia e pobreza: problemas de desenvolvimento energético e grupos sociais marginais em áreas rurais e urbanas do Brasil. Nações Unidas. Comissão Econômica para a América Latina e o Caribe - CEPAL. Divisão de Recursos Naturais e Desenvolvimento, $n^{\circ} 60$. Nações Unidas, Santiago de Chile, 2003. Disponível em: https://www.cepal.org/pt-br/publicaciones/6421-energia-pobreza-problemasdesenvolvimento-energetico-grupos-sociais-marginais. Acesso em: 24 ago. 2014.

SCHMIDT, C. A. J.; LIMA, M. A. M. A. A demanda por energia elétrica no Brasil. Revista Brasileira de Economia, v. 58, n. 1, p. 68-98, 2004.

SILVA, A. S. et al. Knowing electricity end-uses to successfully promote energy efficiency in buildings: a case study in low-income houses in Southern Brazil. International Journal of Sustainable Energy Planning and Management, v. 2, p. 7-18, 2014.

SIQUEIRA, M. L.; CORDEIRO JUNIOR, H. H.; CASTELAR, I. A demanda por energia elétrica no Nordeste brasileiro após racionamento de 2001-2002: previsões de longo prazo. Pesquisa e Planejamento Econômico, v. 36, n. 1, p. 137-178, 2006.

SOUZA, E. C. de et al. Impactos das mudanças climáticas sobre o bem-estar relacionado à saúde no Brasil. Pesquisa e Planejamento Econômico, v. 43, n. 1, p. 49-87, 2013.

SWAN, L. G.; UGURSAL, V. I. Modeling of end-use energy consumption in residential sector: a review of modeling techniques. Renewable and Sustainable Energy Review, v. 13, p. 1819-1835, 2009.

TSO, G. K. F.; GUAN, J. A multilevel regression approach to understand effects of environment indicators and household features on residential energy consumption. Energy, v. 66, n. 1, p. 722-731, 2014.

WOLFRAM, C.; SHELEF, O.; GERTLER, P. How will energy demand develop in the developing world? Journal of Economic Perspectives, v. 26, n. 1, p. 119-138, 2012.

\section{Agradecimentos}

O presente trabalho foi parcialmente realizado com apoio da Coordenação de Aperfeiçoamento de Pessoal de Nível Superior - Brasil (CAPES) - Código de Financiamento 001. 


\section{Karla Cristina de Freitas Jorge Abrahão}

Programa de Pós-graduação em Ambiente Construído e Patrimônio Sustentável, Escola de Arquitetura | Universidade Federal de Minas Gerais | Rua Paraíba, 697, Savassi | Belo Horizonte - MG - Brasil | CEP 30130-141 | Tel.: (31) 3409-8801 | E-mail: kjabrahao@hotmail.com

\section{Roberta Vieira Gonçalves de Souza}

Escola de Arquitetura | Universidade Federal de Minas Gerais | Tel.: (31) 3409-8825 | E-mail: roberta@arq.ufmg.br

\section{Ambiente Construído}

Revista da Associação Nacional de Tecnologia do Ambiente Construído

Av. Osvaldo Aranha, $99-3^{\circ}$ andar, Centro

Porto Alegre - RS - Brasil

$$
\text { CEP } 90035-190
$$

Telefone: +55 (51) 3308-4084

Fax: +55 (51) 3308-4054

www.seer.ufrgs.br/ambienteconstruido

E-mail: ambienteconstruido@ufrgs.br

This is an open-access article distributed under the terms of the Creative Commons Attribution License. 